\title{
Ocular Dominance Column Development: Strabismus Changes the Spacing of Adjacent Columns in Cat Visual Cortex
}

\author{
Siegrid Löwel \\ Max-Planck-Institut für Hirnforschung, D-60528 Frankfurt a.M., Germany
}

To investigate the role of visual experience for the gross layout of ocular dominance (OD) columns in the visual cortex, I compared the respective patterns in normally raised and strabismic cats. OD domains were visualized by (1) transneuronal labeling of the afferents from the left or right eye with intraocular ${ }^{3} \mathrm{H}$-proline injections or (2) ${ }^{14} \mathrm{C}$-2-deoxyglucose autoradiography after monocular visual stimulation in awake animals. To obtain the complete pattern of OD columns, flat-mount sections were prepared from the unfolded cortical hemispheres. Eliminating correlated activity between the two eyes by making the animals strabismic influenced the gross layout of the OD domains. In area 17, OD domains become more sharply delineated than in normal animals and spaced more widely. Spatial frequency analyses revealed a mean spacing of adjacent columns of 1100$1300 \mu \mathrm{m}$ in strabismic and of 800-1000 $\mu \mathrm{m}$ in normal cats. In area 18, the spacing of the ocular dominance domains is larger than in area 17 for both normal and strabismic cats $(1500-1650 \mu \mathrm{m})$, but little influenced by strabismus. These results indicate that in area 17 decreased correlation of activity between the eyes alters the periodicity of OD columns. In addition, these observations suggest that not only the segregation of afferents into distinct columns but also the final expression of the columnar grid is influenced by visual experience, and in particular by the temporal patterning of neural activity. This is further evidence for the hypothesis that the development of OD columns is governed by activitydependent self-organizing principles.

[Key words: area 17, area 18, squint, self-organization, experience dependence, cortical maps]

When kittens are born, the geniculocortical afferents from the two eyes are overlapping in cortical layer IV, the input layer of primary visual cortex (LeVay and Gilbert, 1976; LeVay et al., 1978). The segregation of these projections into alternating

\footnotetext{
Received Dec. 27, 1993; revised May 13, 1994; accepted May 24, 1994.

It is a pleasure for me to thank Wolf Singer for his cooperation, numerous discussions, and constant support. Thanks also to Monika Sum, Sigrid Thel, Regina Krauss, and Evelyn Raulf for expert technical assistance, to Renate RuhlVölsing for superb graphics, to the darkroom team for the photoprints, and to $\mathrm{Mr}$. Bink and the staff of the animal house for excellent animal care. Special thanks are due to Klaus Pawelzik and Olaf Scherf for help with quantitative analyses, to Dae-Shik Kim for programming the visual stimulus for the anesthetized animals and for valuable criticism, to Sergio Neuenschwander for his ideas about graphics, and to Ken Miller, Klaus Pawelzik, and Andreas Kreiter for brainstorming. In addition, I thank two anonymous referees for valuable criticism and constructive comments.

Correspondence should be addressed to Siegrid Löwel, Max-Planck-Institut für Hirnforschung, Deutschordenstrasse 46, D-60528 Frankfurt a.M., Germany. Copyright (C) 1994 Society for Neuroscience $0270-6474 / 94 / 147451-18 \$ 05.00 / 0$
}

patches, called "ocular dominance columns," occurs during early life starting at about 3 weeks of age (LeVay et al., 1978; Shatz and Stryker, 1978). In the past 20 years, a huge number of investigations demonstrated the influence of afferent activity on the development of the ocular dominance columns by using several different experimental paradigms like monocular and binocular deprivation, impulse blockade, dark rearing, and squint. When neuronal activity is completely blocked in the eyes during a critical period early in development, the patches do not develop at all (Stryker and Harris, 1986; see also Meyer, 1982). When neuronal activity is reduccd in the cycs (dark rearing or binocular lid suture) the degree of segregation seems to be reduced as well (Wiesel and Hubel, 1965; Swindale, 1981; Kalil, 1982; Mower et al., 1985). On the other hand, the elimination of correlated activity between the two eyes, as it occurs in strabismus, enhances segregation (Shatz et al, 1977; Kalil, 1982; Löwel and Singer, 1993b). When neuronal activity is reduced in only one eye (monocular deprivation) projections from this eye occupy much less than their normal share of territory in layer IV, while those from the open eye expand (Wiesel and Hubel, 1965; Hubel et al., 1977; Shatz and Stryker, 1978; LeVay et al., 1980). It has been concluded from these studies that the formation of ocular dominance columns is driven by activitydependent competition between the geniculocortical afferents of the two eyes whereby the temporal patterning of neural activity conveys the essential information for the axons to segregate (Stryker and Strickland, 1984). Therefore, many workers in the field interpreted these results as indicating that column formation is the result of a competitive self-organizing process (for review, see Stryker, 1986, 1991; Constantine-Paton, 1983; Constantine-Paton et al., 1990; Goodman and Shatz, 1993). Whether similar mechanisms are also responsible for the final expression of the columnar pattern, that is, for the spacing of adjacent columns, their width, and location, is less well investigated. If one could demonstrate that these parameters can also be influenced by visual experience one would have compelling evidence that the development of ocular dominance columns is indeed determined by activity-dependent self-organizing principles and not by factors intrinsic to the cortex and independent of properties of the cortical inputs, as recently suggested by Jones et al. (1991).

To investigate the role of visual experience and in particular the temporal patterning of activity for the gross layout of ocular dominance columns, I analyzed these domains in strabismic cats, paying particular attention to the spacing of adjacent domains. For comparison, normally raised control animals were analyzed. All strabismic cats of the present study had a surgically induced divergent squint angle. As a consequence of the misalignment of the optical axes, the activities in the geniculocor- 
Table 1. List of all cats used to visualize ocular dominance columns

\begin{tabular}{|c|c|c|c|c|c|c|c|c|}
\hline \multirow[b]{2}{*}{ Cat } & \multirow[b]{2}{*}{ Cortex } & \multirow{2}{*}{$\begin{array}{l}\text { Age } \\
\text { (weeks) }\end{array}$} & \multirow{2}{*}{$\begin{array}{l}\text { Weight } \\
(\mathrm{gm})\end{array}$} & \multirow{2}{*}{$\begin{array}{l}\text { Number of } \\
\text { sections }\end{array}$} & \multirow[b]{2}{*}{ Method } & \multicolumn{2}{|c|}{ OD spacing $(\mu \mathrm{m})$} & \multirow{2}{*}{$\begin{array}{l}\text { Length } \\
\text { of area } \\
17 \\
(\mathrm{~mm})\end{array}$} \\
\hline & & & & & & Area 17 & Area 18 & \\
\hline \multirow[t]{2}{*}{ S1 } & Right & 8 & 840 & 58 & 2-DG & 1250 & & 38 \\
\hline & Left & & & 64 & & 1270 & 1550 & 39 \\
\hline \multirow[t]{2}{*}{$\mathbf{S} 2$} & Right & 13 & 1510 & 59 & $2-\mathrm{DG}$ & 1220 & & 39 \\
\hline & Left & & & 65 & & 1250 & 1500 & 39 \\
\hline S3 & Right & 8.5 & 980 & 60 & $\begin{array}{l}\text { Proline } \\
\qquad(+2-D G)\end{array}$ & 1200 & & 38 \\
\hline S4 & Left & 9 & 1000 & 62 & $\begin{array}{l}\text { Proline } \\
\qquad(+2-D G)\end{array}$ & 1160 & 1650 & 37 \\
\hline \multirow[t]{2}{*}{ S5 } & Right & 10 & 940 & 52 & 2-DG & 1150 & 1500 & 34 \\
\hline & Left & & & 53 & & 1180 & & 35 \\
\hline \multirow[t]{2}{*}{ S6 } & Right & 10 & 1120 & 56 & 2-DG & 1110 & & 35 \\
\hline & Left & & & 54 & & 1200 & & \\
\hline N1 & Left & 15 & 1300 & 54 & Proline & 960 & & 35 \\
\hline \multirow[t]{2}{*}{ N2 } & Right & 9.5 & 850 & 57 & $2-\mathrm{DG}$ & 1020 & 1600 & 40 \\
\hline & Left & & & 60 & & 940 & & 40 \\
\hline \multirow[t]{2}{*}{ N3 } & Right & 10.5 & 1080 & 59 & 2-DG & 930 & & 40 \\
\hline & Left & & & 62 & & 1000 & & 40 \\
\hline \multirow[t]{2}{*}{ N4 } & Right & 12 & 1200 & 65 & Proline & 770 & & 33 \\
\hline & Left & & & 70 & & 800 & & 33 \\
\hline \multirow[t]{2}{*}{ N5 } & Right & 12 & 1200 & 65 & Proline & 850 & & 32 \\
\hline & Left & & & 58 & & 830 & 1650 & 32 \\
\hline
\end{tabular}

Cat, "name" of the animal. Cortex, hemisphere used for the analysis of the OD spacing. Age (in weeks), age of the cats. Weight, body weight (in grams) of the cats. Number of sections, number of cortical flat-mount sections. Method, technique used to visualize ocular dominance columns. OD spacing, spacing of adjacent ocular dominance domains determined by spatial frequency analysis of the autoradiographs. Length of area 17, anterior-posterior extension (in millimeters) of area 17. S, strabismic; N, "normal"; 2-DG, 2-deoxyglucose; OD, ocular dominance column.

tical afferents of the two eyes are no longer correlated and most cells in the visual cortex become responsive exclusively to stimulation of either the right or the left eye (Hubel and Wiesel, 1965). However, these monocularly driven cell populations are capable of subserving normal pattern vision. To avoid double vision, strabismics use only one eye at a time and suppress the signals from the other eye (von Noorden, 1990). Taken together, the amount of neural activity reaching the cortex via the geniculocortical afferents should be similar for normal and squinting cats, whereas the temporal patterning of activity is different.

Some of these results have been reported in abstract form (Löwel and Singer, 1993c,d).

\section{Materials and Methods}

A total of 11 cats were used in this study (see Table 1). All animals had already been subjects of other investigations (Löwel and Singer, 1987, 1992, 1993a,b). In six kittens from four different litters (S1/S2, S3/S4, S5, and S6), divergent strabismus was induced surgically at the age of 2-3 weeks. The remaining five kittens from three different litters $(\mathrm{N} 1$, $\mathrm{N} 2 / \mathrm{N} 3, \mathrm{~N} 4 / \mathrm{N} 5$ ) were normally raised (controls). Ocular dominance columns were visualized with two different techniques: (1) anatomically by intraocular ${ }^{3} \mathrm{H}$-proline injections (Grafstein, 1971; Wiesel et al., 1974) and/or (2) functionally with ${ }^{14} \mathrm{C}$-2-deoxyglucose after monocular stimulation (Sokoloff et al., 1977). The normally raised cats were awake and freely exploring the laboratory during the monocular 2-DG experiments, and the strabismics were either awake or anesthetized and paralyzed (Löwel and Singer, 1993a,b).

Surgical procedures and visual stimulation. For the induction of strabismus, anesthesia was induced with ketamine hydrochloride $(10 \mathrm{mg} /$ $\mathrm{kg}$ body weight) and xylazine hydrochloride $(2.5 \mathrm{mg} / \mathrm{kg})$ intramuscularly, and maintained with ketamine hydrochloride intravenously. In all six kittens, the medial rectus muscle of the left eye was severed to induce divergent strabismus.

For transneuronal labeling of ocular dominance columns in layer IV, two strabismics and three normally reared cats were anesthetized as above (ketamine/xylazine) and then injected with $2-2.5 \mathrm{mCi}$ of ${ }^{3} \mathrm{H}$ proline (Amersham; injected volume $50 \mu \mathrm{l}$ in cats N1, N5, S3, and S4, and $25 \mu \mathrm{l}$ in cat N4) in one eye (the right eye in cats N4, N5, S3, and S4; the left eye in cat N1) (see Table 1).

At the age of 2-3 months, in four strabismic (S1, S2, S3, S4) and two normally raised cats (N2, N3) one eye was occluded and a venous catheter implanted under halothane anesthesia ( $1-4 \%$ halothane in a mixture of $70 \% \mathrm{~N}_{2} \mathrm{O}, 30 \% \mathrm{O}_{2}$ ). After full recovery from anesthesia, 2-deoxy-D-U14 C-glucose (2-DG, Amersham; specific activity, $310 \mathrm{mCi}$ / $\mathrm{mmol} ; 100-120 \mu \mathrm{Ci} / \mathrm{kg}$ ) was injected and the cats were allowed to move freely around in the laboratory for effective monocular stimulation.

The remaining two strabismic cats $(\mathbf{S 5}, \mathrm{S6})$ were prepared for a "conventional" 2-DG experiment (under anesthesia and paralysis) as described in detail elsewhere (Löwel et al., 1987; Löwel and Singer, 1993a). Therefore, only the essential steps of the preparation are reported. Anesthesia was induced as described above and, after tracheal intubation and cannulation of a femoral vein, was maintained with a mixture of $70 \% \mathrm{~N}_{2} \mathrm{O}, 30 \% \mathrm{O}_{2}$. The animal's head was fixed in a stereotaxic frame by means of a metal bar cemented to the skull and a muscle relaxant (hexcarbacholinbromide, $10 \mathrm{mg}$ in $45 \mathrm{ml}$ of Ringer, $3 \mathrm{ml} / \mathrm{kg} / \mathrm{hr}$ ) was applied to prevent eye movements. All wound edges were infiltrated with xylocaine. As with standard electrophysiological recordings, the body temperature, ECG, EEG, pulmonary pressure, and $\mathrm{CO}_{2}$ content of the expired air were continuously monitored. End-tidal $\mathrm{CO}_{2}$ and rectal temperature were kept in the range of $3-4 \%$ and $37-38^{\circ} \mathrm{C}$, respectively. Both animals were stimulated monocularly through the right eye; therefore, the left (nonstimulated) eye was covered with a black contact lens and an additional black patch. Simultaneously with the onset of light stimulation, the animals received an intravenous injection of 2-deoxyD- ${ }^{\mathrm{U}}{ }^{4} \mathrm{C}$-glucose (Amersham; specific activity, $310 \mathrm{mCi} / \mathrm{mmol}$; 110-125 
$\mu \mathrm{Ci} / \mathrm{kg}$ ) at a rate of $25 \mu \mathrm{Ci} / \mathrm{min}$. Visual stimulation was monocular and consisted of moving square wave gratings that covered the central $20^{\circ}$ of the visual field. A $1.5^{\circ}$ wide strip along the vertical meridian was stimulated with horizontal contours only, whereas the orientation of the grating in the remaining visual field changed every $5 \mathrm{sec}$ in $45^{\circ}$ steps (spatial frequency, $1,0.5$, and 0.15 cycles/degree; velocity, 2 cycles/ degree).

Histological procedures. After 45 min of visual stimulation, the " 2 DG" animals were given a lethal dose of Nembutal injected intravenously. The "proline" animals received a similar overdose of Nembutal after a survival time of 2 weeks (which is needed for the transneuronal transport of the radioactively labeled proline).

The occipital poles of the brains were removed and the visual cortices flat-mounted prior to freezing the tissue on dry ice (Freeman et al., 1987). To provide landmarks for superposition of adjacent sections, three holes were made in the flat-mounts with warm needles. Subsequently, 26- $\mu \mathrm{m}$-thick serial cryostat sections were cut parallel to the cortical surface. The sections were mounted on glass slides and immediately dried on a hot plate. For ${ }^{14} \mathrm{C}-2-\mathrm{DG}$ autoradiography, they were exposed to $x$-ray film (Agfa Mamoray M4) for 3-4 weeks. For the visualization of the ${ }^{3} \mathrm{H}$-proline distributions, the sections were postfixed in $4 \%$ paraformaldehyde (in the double-labeling experiments, washed to remove all ${ }^{14} \mathrm{C}-2-\mathrm{DG}$, ) and then exposed to Ultrofilm (LKB) for 812 weeks (Löwel et al., 1988). [To control for the possibility that the ${ }^{3} \mathrm{H}$-proline had contributed to the darkening of the ${ }^{14} \mathrm{C}-2-\mathrm{DG}$ autoradiographs, the sections were exposed a second time, after washout of ${ }^{14} \mathrm{C}-2-\mathrm{DG}$ (now only ${ }^{3} \mathrm{H}$ should be contained in the sections), to the $\mathrm{x}$-ray films (sensitive to ${ }^{14} \mathrm{C}$ ). These controls never revealed any substantial labeling on the ${ }^{14} \mathrm{C}$ films.]

Image processing and data analysis. Although we had unfolded the cortex, single flat-mount sections never covered the full extent of layer IV and therefore did not contain the complete pattern of ${ }^{3} \mathrm{H}$-prolinelabeled ocular dominance columns (which are restricted to layer IV). To obtain the complete pattern a photomontage of all label-containing regions was made, using the needle holes as guidelines for the correct superposition of serial sections.

The ${ }^{14} \mathrm{C}$-labeled ocular dominance columns extend in columns through all cortical layers (Löwel and Singer, 1992, 1993b). Therefore, single autoradiographs always contain the complete pattern of ocular dominance columns and reconstructions were not necessary.

The mean spacing of columns was determined by spatial frequency analysis. To this end, ${ }^{3} \mathrm{H}$-proline and ${ }^{14} \mathrm{C}$-2-DG autoradiographs were analyzed with a digital image processing system (IMAGO II, Compulog). The density distributions of the $\mathrm{x}$-ray films were coded in digital units, ranging from 1 to 256. Average columnar spacing was determined by one-dimensional Fourier analyses along multiple vectors perpendicular to the columnar boundaries. Since ocular dominance domains have a small tendency to be elongated orthogonal to the $17 / 18$ border (Löwel and Singer, 1987; Anderson et al., 1988), most measurements were performed parallel to that border, that is, in an anterior-posterior direction (perpendicular to the long axis of elongated slabs, a direction most probably unaffected by "unfolding" artifacts; see below).

As an indication of the size of area 17, its length was determined by measuring the extension of the area showing (1) ocular dominance domains or (2) "area 17-specific" 2-DG labeling (in the anesthetized cats S5 and S6) on the autoradiographs in an anterior-posterior direction. I did not attempt to determine the surface area of area 17 because flatmounts may get compressed in a mediolateral direction during unfolding (the gyri and sulci extend predominantly in an anterior-posterior direction so that incomplete unfolding would result in a compression of the autoradiographs in a mediolateral direction).

\section{Results}

\section{General}

In the present study, ocular dominance domains were visualized with two different techniques: (1) anatomically by transneuronal labeling of the geniculocortical input to layer IV of visual cortex after intraocular ${ }^{3} \mathrm{H}$-proline injections and (2) functionally with ${ }^{14} \mathrm{C}-2-\mathrm{DG}$ autoradiography after monocular visual stimulation. Since monocularly activated $2-\mathrm{DG}$ columns are in precise register with the termination zones of the afferents from the activated eye in layer IV (Löwel and Singer, 1992, 1993b) the two techniques give essentially similar results. The only difference is that proline-labeled ocular dominance domains arc restricted to layer IV (LeVay and Gilbert, 1976), whereas the 2-DG labeling extends in a columnar fashion through all cortical layers (Löwel and Singer, 1993b).

\section{Layout of ocular dominance domains in area 17}

As described previously (Löwel and Singer, 1993b), in strabismics the 2-DG and proline patterns display all the features characteristic of ocular dominance domains (Figs. 1, 2; for additional comparison with normally raised cats, see Löwel and Singer, 1987; Anderson et al., 1988): (1) The optic disk representations of the stimulated or injected eye are identifiable in the posterior third of the hemispheres as demarcated oval regions that are solidly labeled ipsilateral to the open or injected eye and unlabeled on the contralateral side. (2) The monocular segment is indicated by uniform labeling at the medial border of the arca 17 contralateral to the stimulated or injected eye and by the absence of labeling at comparable eccentricity on the ipsilateral side. (3) The territories of the stimulated or injected eye tend to be larger in the contra- than in the ipsilateral hemispheres.

\section{"Sharpness" of the segregation of ocular dominance columns in area 17}

The reconstructions of the complete pattern of ocular dominance columns in strabismic cats confirm observations of an older study by Shatz et al. (1977): Patches of label representing the ipsi- or contralateral eye were more distinct than in normal cats, most likely due to a decrease in the amount of label distributed between patches (compare Fig. $1 A, B$ ). Artificially induced squint therefore appears to decrease the volume of layer IV shared by afferents from the two eyes, which is consistent with the elcctrophysiological observations of reduced binocularity in these animals (Hubel and Wiesel, 1965).

\section{Spacing of ocular dominance columns in area 17}

In addition to the reported differences between the patterns of ocular dominance columns of strabismic and normally raised cats, the spacing of adjacent domains is also altered in squinting cats. To illustrate this observation, complete reconstructions of ocular dominance domains in all six strabismic cats and in four of the five normally raised control animals are shown here (compare Figs. $1 A, 4 A-F$ with Figs. $1 B, 2,3 A-F$ ).

To quantify this difference in spacing, the spectral content of the pattern of ocular dominance columns was analyzed by onedimensional Fourier analyses along vectors perpendicular to the columnar boundaries. Although ocular dominance columns in both strabismic and normal cats are rather patchy, numerous elongated slabs and short bands arc also present (see, e.g., the ocular dominance domains adjacent to the optic disk representations in Fig. $1 A, B$ or in general the pattern of ocular dominance columns of the strabismic cat in Fig. $1 B$ ). Vectors were therefore oriented perpendicular to the long axis of these slabs. Since ocular dominance columns have a small tendency to elongate orthogonal to the $17 / 18$ border (Löwel and Singer, 1987; Anderson et al., 1988), measurements were performed predominantly in an anterior-posterior direction. Figure 5 shows that the resulting one-dimensional Fourier spectra for the normal cats peak at values between $770 \mu \mathrm{m}$ and $1020 \mu \mathrm{m}$ (mean value, $900 \pm 85 \mu \mathrm{m}$ ), while those of the strabismics range between $1110 \mu \mathrm{m}$ and $1270 \mu \mathrm{m}$ (mean value, $1199 \pm 48 \mu \mathrm{m}$; see also Table 1). Figure 6 shows that the two distributions are not only 
A

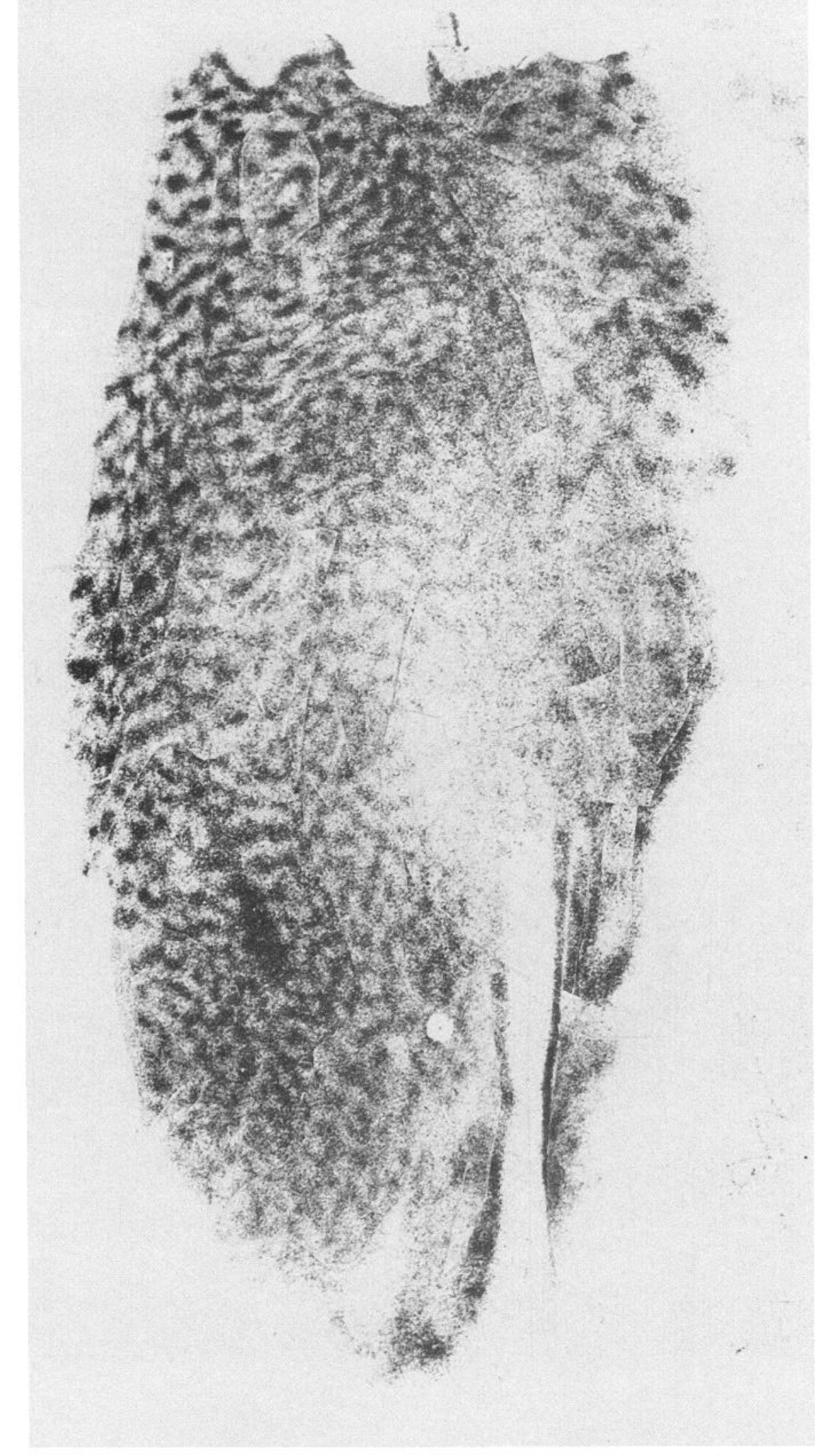

\section{ant}

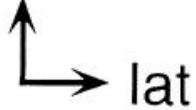

Figure 1. Overall pattern of the ocular dominance columns in the visual cortex of the normally raised cat $\mathrm{N} 4(A)$ and the strabismic cat S3 $(B$, $C$ ): photographic reconstruction of the ${ }^{3} \mathrm{H}$-proline-labeled columns in layer IV ipsilateral to the injected eye $(A, B)$ and a graphical reconstruction (by hand-drawing successive sections) of the pattern in $B(C)$. The optic disk representations appear in the posterior third of area 17 as oval and 

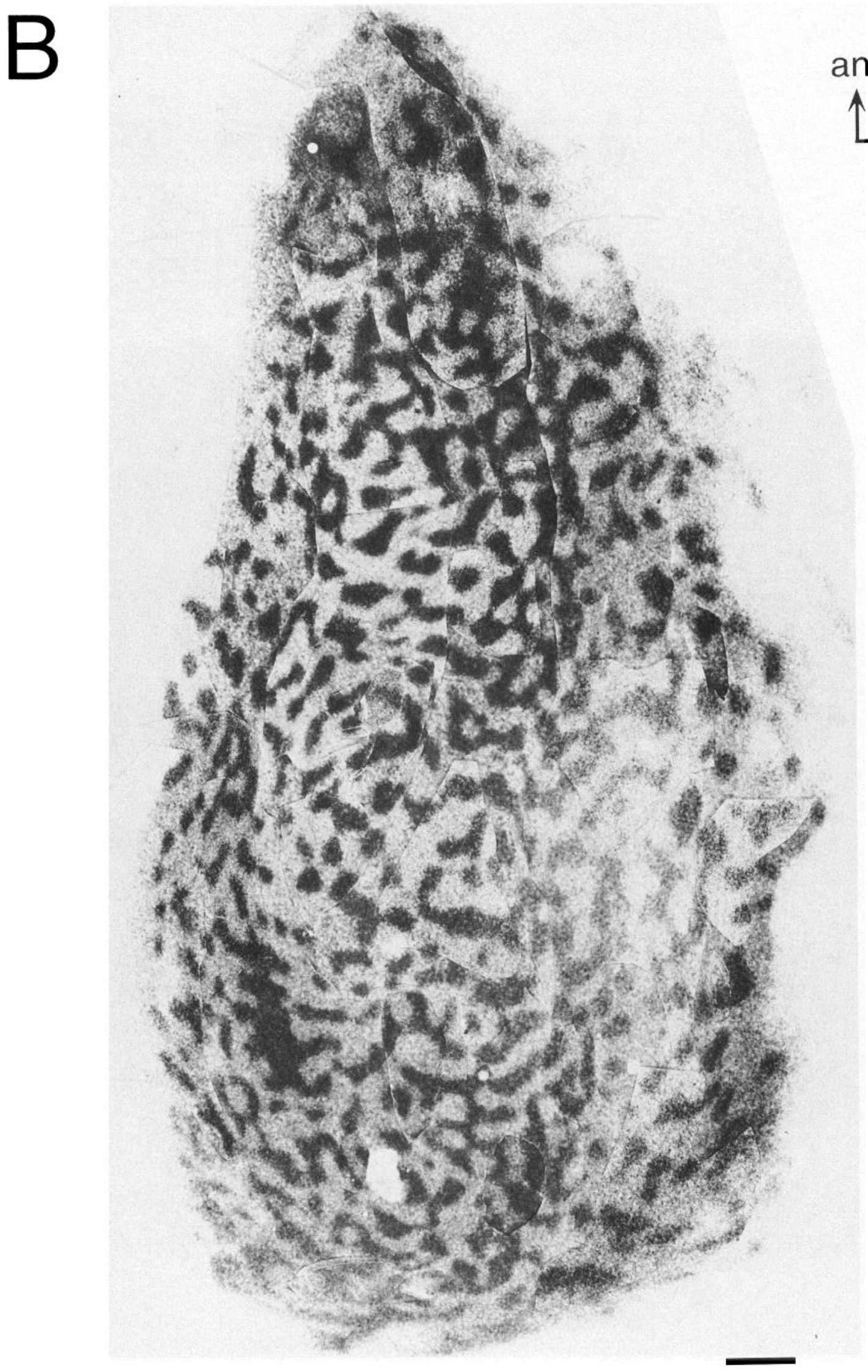

solidly labeled regions (downward to the left). Note the sharp delineation of labeled (dark gray) and unlabeled (light gray) territories, which is more pronounced in the strabismic animal. Note in addition that the periodicity of the ocular dominance columns is wider in the strabismic animal. ant, anterior; lat, lateral. Scale bar, $2 \mathrm{~mm}$. 

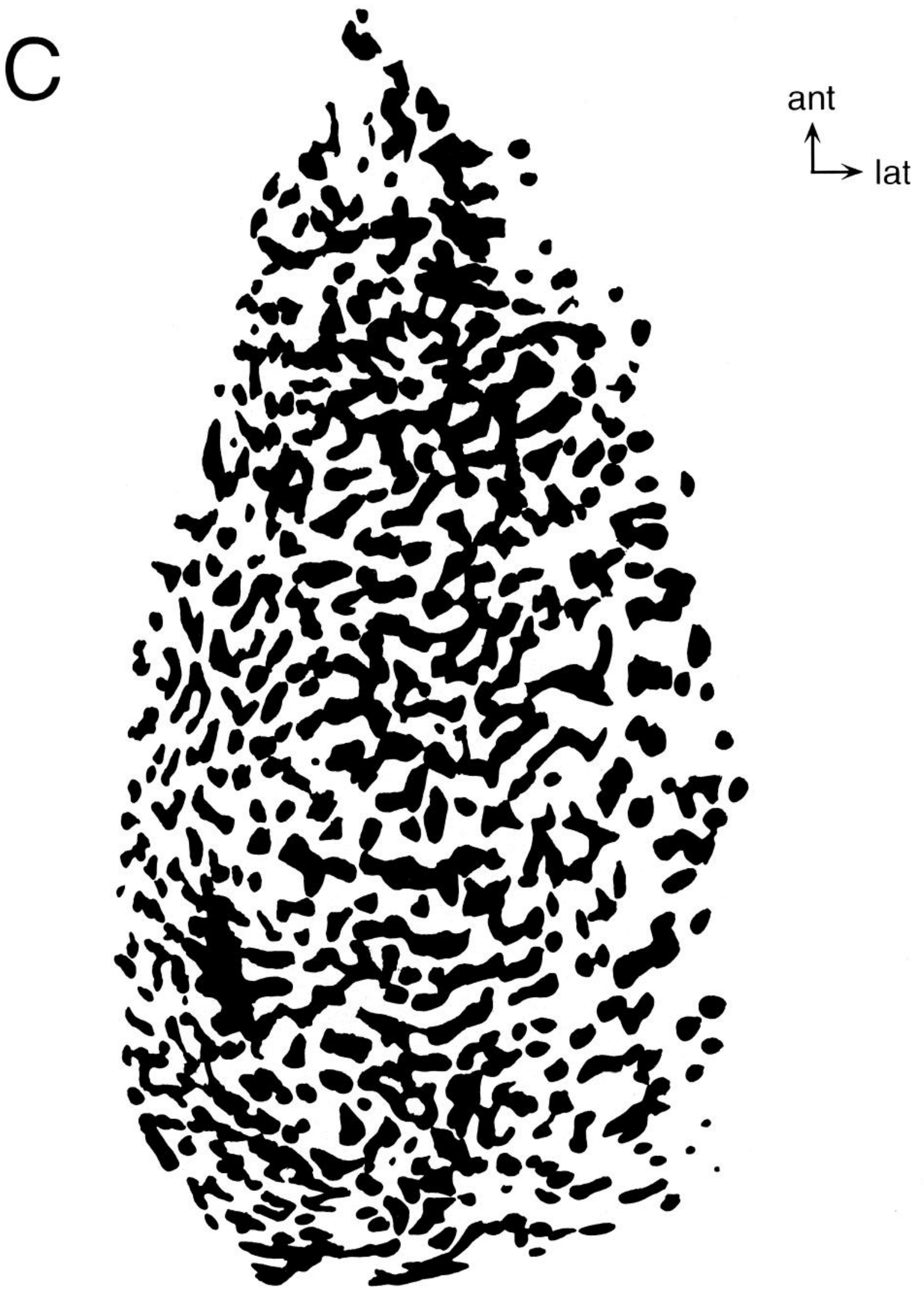
different but essentially nonoverlapping: none of the strabismic cats had a spacing of ocular dominance columns in the range of normally raised animals and vice versa.

The values obtained for the normally raised cats are in good agreement with other reports in the literature (Fig. 6): Shatz et al. (1977) measured distances of $1 \mathrm{~mm}$; LeVay et al. (1978), $850 \mu \mathrm{m}$; and Diao et al. (1990), $0.8 \pm 0.2 \mathrm{~mm}$ (the measurements of Löwel and Singer, 1987, are contained in the present report). Taken together, in area 17 of strabismic cats ocular dominance domains are on average spaced 1.3 times more widcly than in animals with normal visual experience.

To exclude that those differences in spacing were due to differences in age or weight of the animals, I related spacing to these variables. As Figure $7, A$ and $B$ indicates, there does not seem to be a systematic relationship between these variables. Interestingly, however, the largest columnar spacing of all cats $(1270 \mu \mathrm{m})$ was obtained in the youngest and lightest cat that was one of the squinting animals ( 8 weeks, $840 \mathrm{gm}$ ). In addition, the strabismic cats of the present study were on average younger (mean value, $9.8 \pm 1.6$ weeks) and lighter $(1065 \pm 216 \mathrm{gm})$ than the normal controls (mean value, $11.8 \pm 1.9$ weeks; 1126 $\pm 155 \mathrm{gm}$; see also Table 1 ). In addition, the possibility needs to be considered that the cortical flat-mounts of the strabismic cats had been more compressed during flattening than those of the normal animals, leading to larger columnar spacings in the former than in the latter. To test that possibility, the number of flat-mount sections obtained in the normal and strabismic cases was compared. If compression would have been responsible for the differences, then fewer flat-mount sections should have been obtained from the (more compressed?) cortices of the squinting animals. Figure $7 C$ shows that this was not the case. The number of flat-mount sections was comparable in strabismic (52-65; mean value, $58.3 \pm 4.3)$ and normal cats $(54-70$; mean value, $61.1 \pm 4.6$ ). A final control consisted of the assessment of the length of area 17. To this end, the extension of area 17 was determined in an anterior-posterior direction on the autoradiographs (for details, see Materials and Methods). In strabismic cats, values ranged from 34 to $39 \mathrm{~mm}$ (mean value, $37.1 \pm 1.9 \mathrm{~mm}$ ), and in the normal cats from $32-40 \mathrm{~mm}$ (mean, $36.1 \pm 3.6 \mathrm{~mm}$; see Table 1, Fig. $7 D$ ). These values are in good agreement with another report in the literature: area 17 of the normally raised cats of Anderson et al. (1988) measured $35 \mathrm{~mm}$ anteroposteriorly (range, $32-38 \mathrm{~mm}$ ). Therefore, strabismic and normally raised animals do not differ significantly in the extension of their area 17 and the observed difference in columnar spacing cannot be due to a different length of area 17 .

To quantify the relationships between the various variables (age, body weight, number of sections, length of area 17, strabismus or normal) and the spacing of adjacent ocular dominance columns, the correlation matrix of all variables was examined. The correlation coefficient (c.c.) between the visual experience of the animals (strabismic or normal) and columnar spacing was the largest of all correlations (c.c. 0.91), even larger than the coefficient between the age of the animals and their body weight (c.c. 0.86). Therefore, the statement that the spacing of ocular dominance columns is dependent on whether the cats are squinting or not is at least as significant as the statement that cats gain weight with increasing age. Age (c.c. -0.44$)$, body weight (c.c. -0.16 ), number of sections (c.c. -0.31 ), and length of area 17 (c.c. 0.50 ) are much less strongly correlated with columnar spacing than visual experience. The latter correlation coefficients are similar to the one between age of the animals and length of area
17 (c.c. -0.38 ), that is, similar to the statement that area 17 gets smaller with increasing age. Given these comparisons, the only meaningful statements seem to be those with the highest correlation coefficients: (1) that animals get heavier when they get older (c.c. 0.86), which is trivial, and (2) that columnar spacing strongly depends on the visual experience of the animals (c.c. 0.91). Therefore, visual experience (strabismic or normal) is the only variable that is significantly correlated with the spacing of adjacent ocular dominance columns (c.c. 0.91).

Columnar spacing is similar in the two hemispheres of the same animal. The intraindividual variability is $2-9 \%$ (the respective larger spacings set to $100 \%$ ), compared to the interindividual variability of $14 \%$ in the strabismic and $32 \%$ in the normal animals (see Table 1).

\section{Ocular dominance domains in area 18}

In four strabismic and two normally raised animals, area 18 could be demarcated with sufficient reliability to analyze the proline and 2-DG patterns in this part of the visual cortex. In all squinting animals, well segregated ocular dominance domains were present in area 18 (Fig. 8), both in the proline and 2-DG autoradiographs (compare Fig. $8 A, B$ ). As in area 17, proline-labeled ocular dominance domains are restricted to layer IV, whereas the 2-DG-labeled domains extend in columns through all cortical layers. These observations indicate that not only the thalamocortical afferents of the two eyes are well segregated in area 18 of squinting cats, as has been described before (Shatz et al., 1977), but that in addition, as in area 17, monocularly induced activity patterns are columnar and in register with the terminal patches in layer IV.

\section{Spacing of ocular dominance columns in area 18}

Although area 18 is much smaller than area 17 and therefore less accessible to quantitative analyses, columnar spacing was determined by one-dimensional spatial frequency measurements. The respective Fourier spectra of the strabismic cats peak at values between $1500 \mu \mathrm{m}$ and $1650 \mu \mathrm{m}$ (Fig. $9 A$; mean value $1550 \mu \mathrm{m}$ ), those of the normals at $1600 \mu \mathrm{m}$ and $1650 \mu \mathrm{m}$ (Fig. $9 B$, mean value $1625 \mu \mathrm{m}$ ). Figure $9 C$ shows that the two distributions are overlapping, whereby the spacing of adjacent ocular dominance columns is on average slightly smaller in strabismic compared to normal cats. This trend is also present when measurements in the literature are included: According to Shatz et al. (1977), ocular dominance columns have a spacing of about $1600-1800 \mu \mathrm{m}$ in this visual cortical area (measured on the published photoprints); Cynader et al. (1987) give values of 1.86 $\mathrm{mm}$; and Diao et al. (1990) described a spacing of $2.0 \mathrm{~mm}$.

\section{Comparison of the spacing of ocular dominance columns in areas 17 and 18}

In area 18 , ocular dominance columns are more widely spaced compared to area 17 both in strabismic and normally reared cats (Fig. 9D; compare also Figs. 6, 9C). There are, however, important differences in the ratio of columnar spacings (area 17 vs area 18) between the two experimental groups: in our normally raised animals, ocular dominance domains in area 18 are 1.6-2.0 times larger than in area 17 (Table 1, Fig. 9D). These values are in good agreement with numbers given in the literature: Shatz et al. (1977) described that in normal cats, ocular dominance columns in area 18 are "almost doubled" in size 


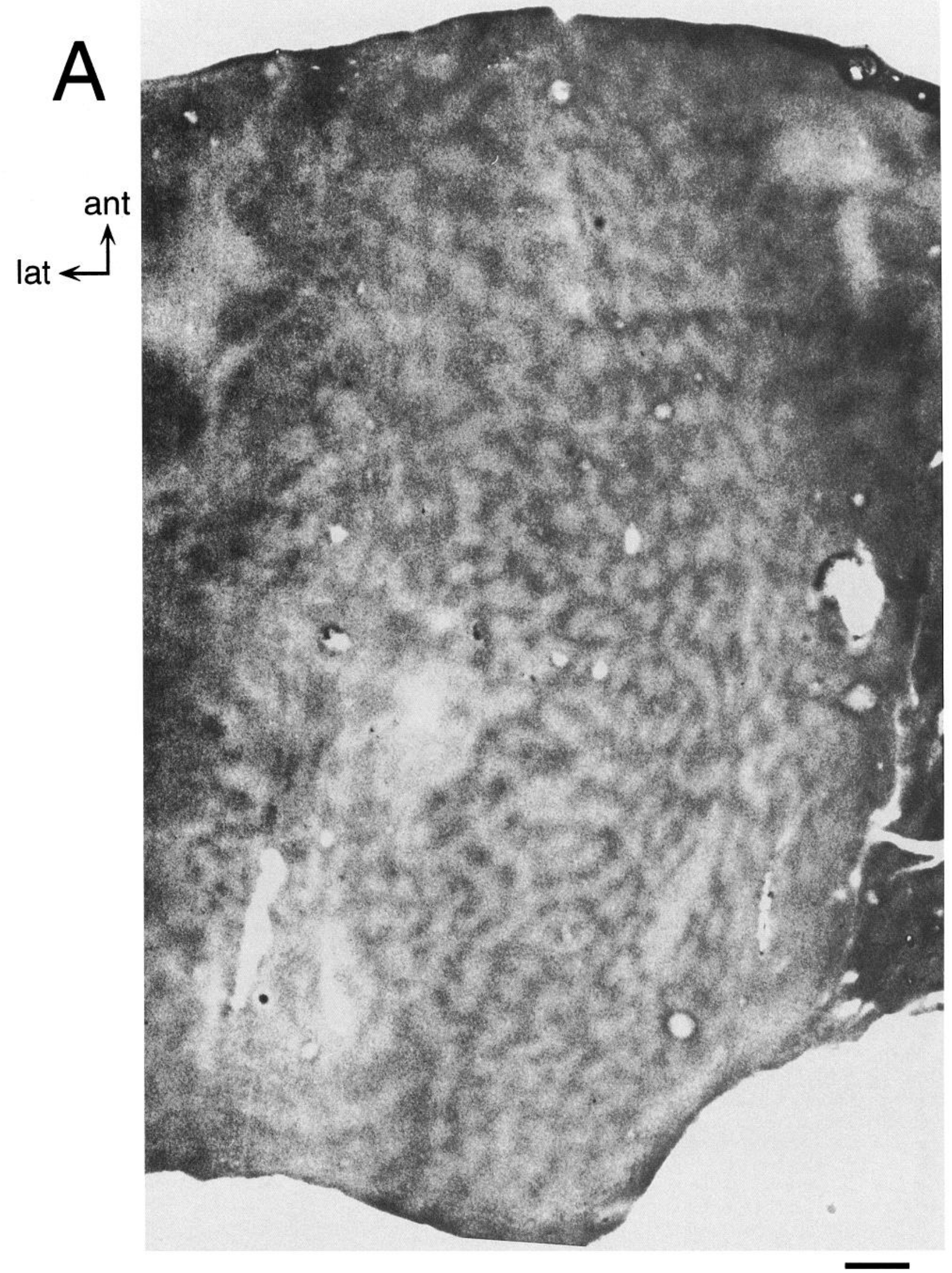

Figure 2. The complete pattern of ocular dominance columns in the visual cortex of two other strabismic cats. $A$, Animal S1 had been stimulated through the right eye. 2-DG autoradiograph of a supragranular flat-mount section from the left (contralateral) hemisphere. $B$, Photographic 


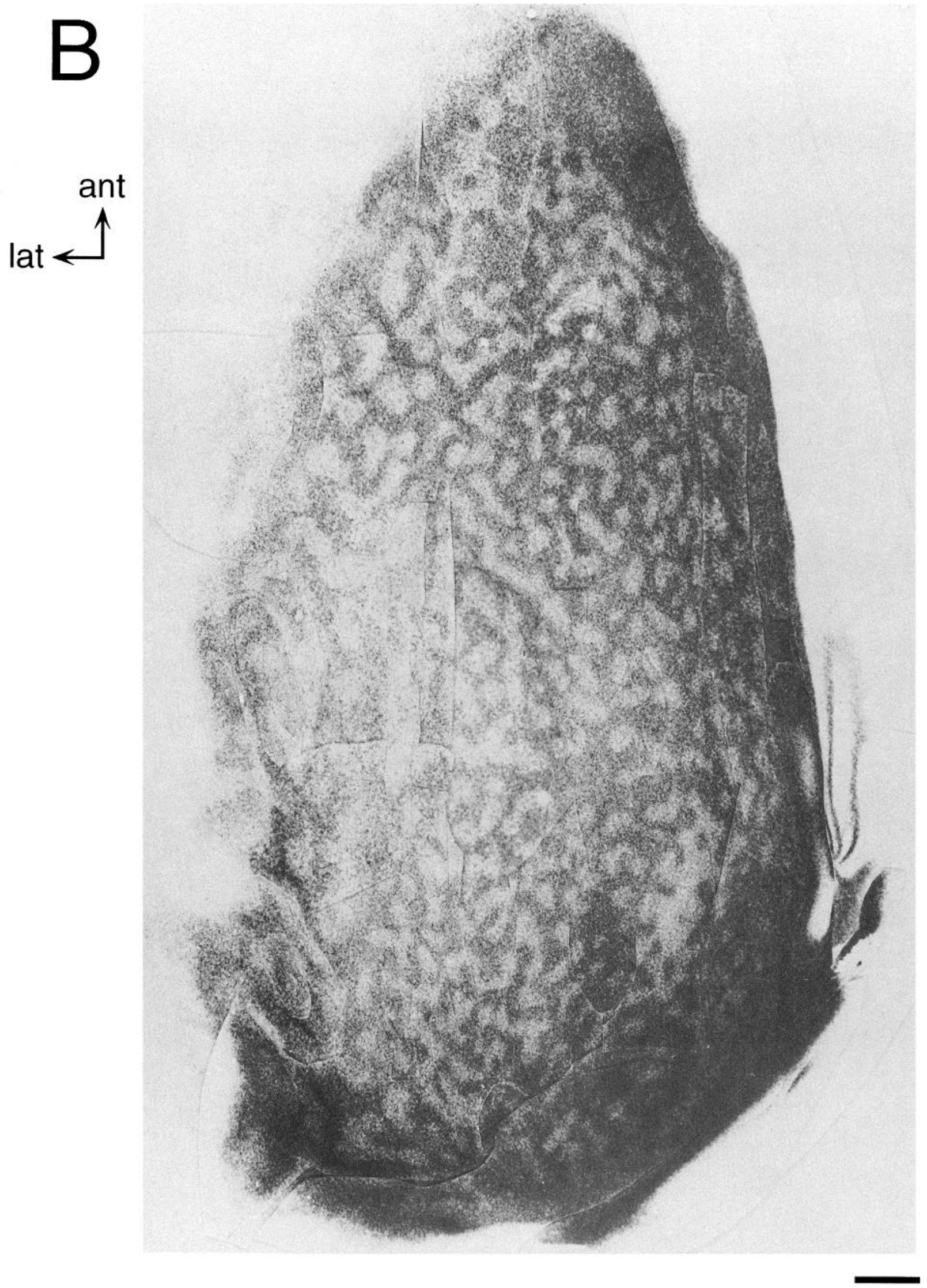

reconstruction of the ${ }^{3} \mathrm{H}$-proline-labeled columns in layer IV contralateral to the injected eye in cat $\mathrm{S} 4$. In both cases, the optic disk representations appear in the posterior third of area 17 as oval and only lightly labeled regions. The monocular segments correspond to the heavily labeled regions at the medial border of area 17 (to the right). ant, anterior; lat, lateral. Scale bar, $2 \mathrm{~mm}$. 

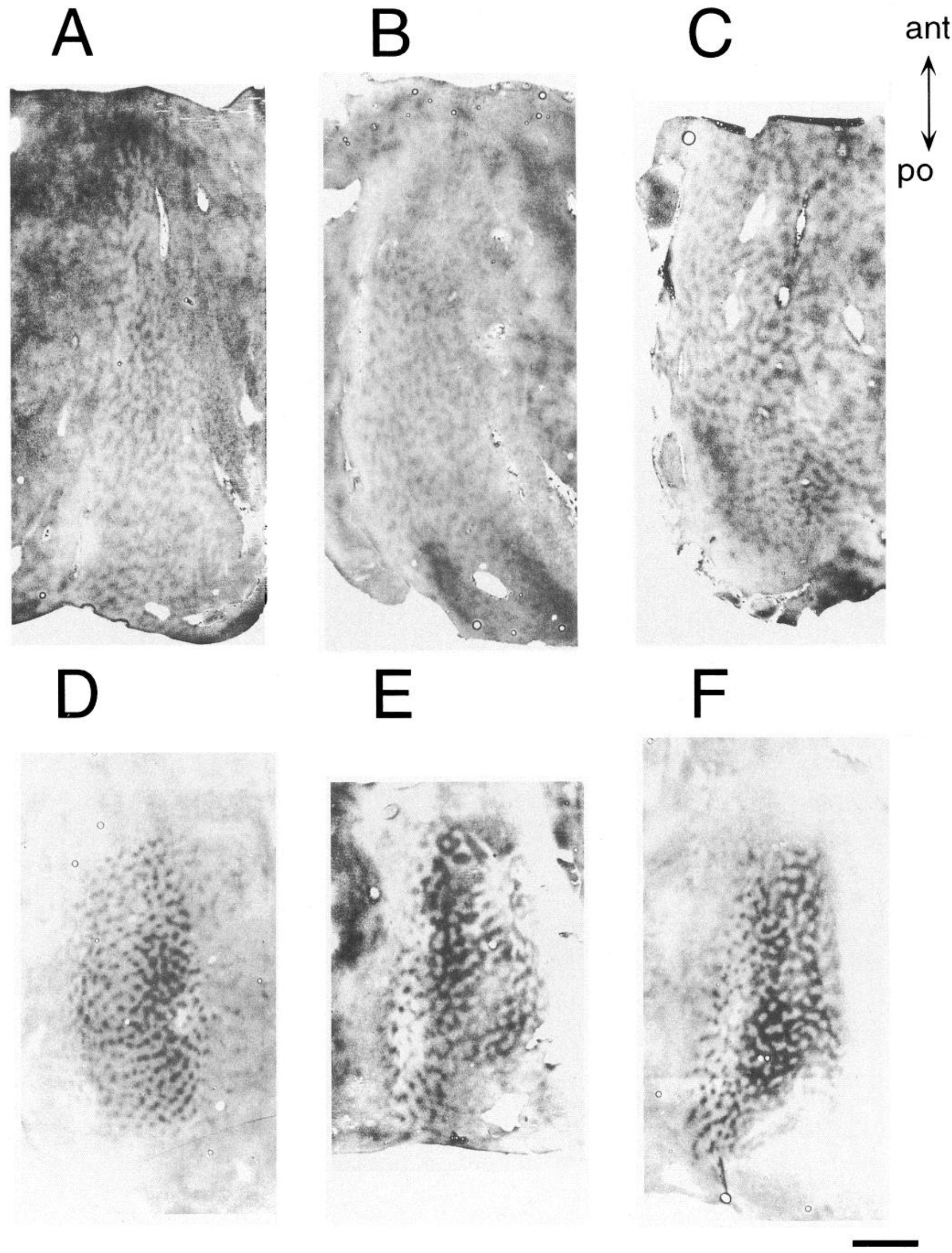

Figure 3. The pattern of ocular dominance columns in the visual cortex of strabismic cats: 2-DG autoradiographs from another six hemispheres in four different animals. $A$ and $B$, Left $(A)$ and right $(B)$ visual cortex of cat $\mathrm{S} 2$. $C$, Right hemisphere of cat S1. $D$ and $F$, Right $(D)$ and left $(F)$ hemisphere of cat S5. E, Left visual cortex of cat S6. Note that cats S1 and S2 were awake during the monocular 2-DG experiments while cats S5 and S6 were anesthetized and paralyzed, and only the central $20^{\circ}$ of the visual field was stimulated visually. 

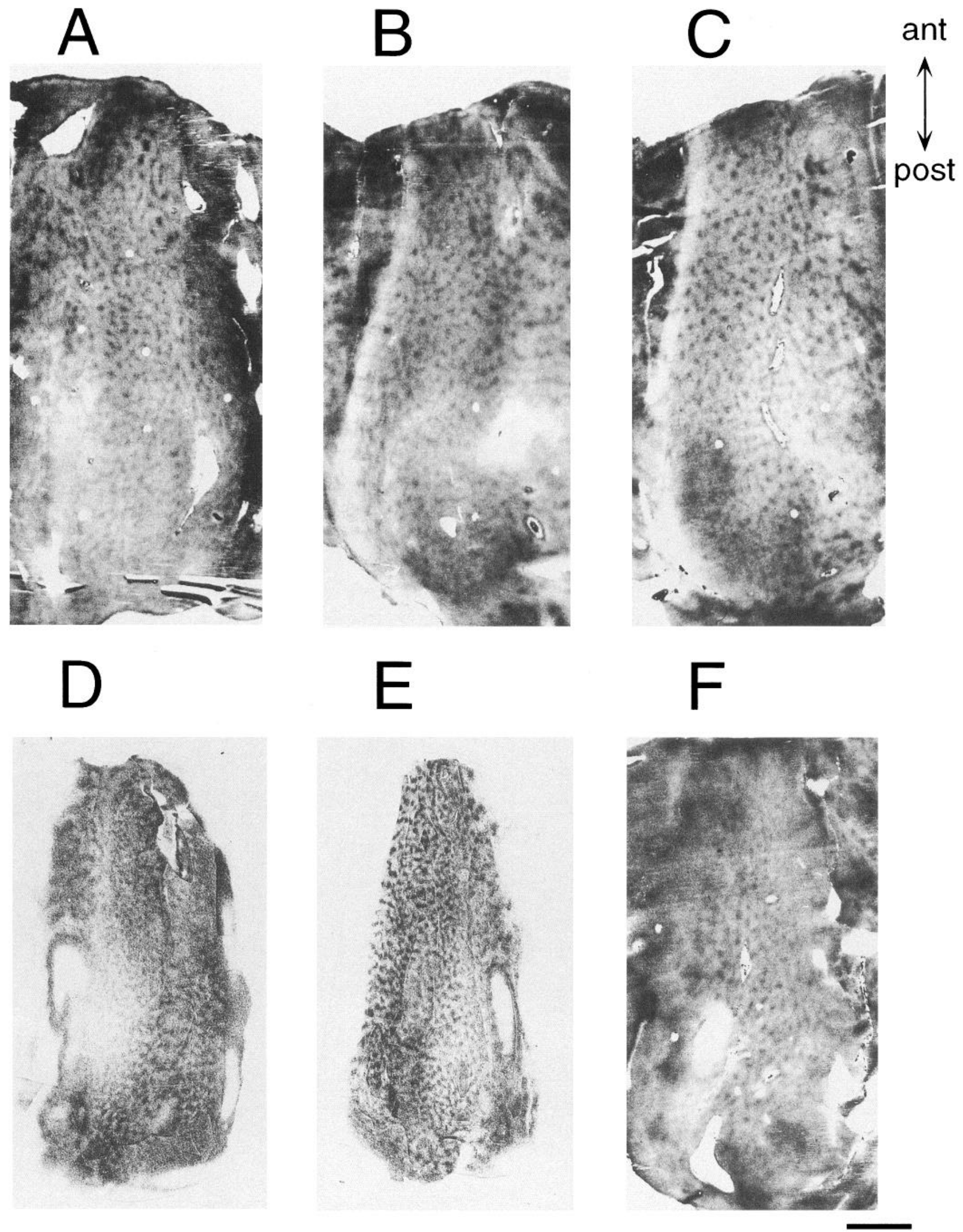

Figure 4. The pattern of ocular dominance columns in the visual cortex of normally raised cats: ${ }^{14} \mathrm{C}-2$-DG $(A-C, F)$ and ${ }^{3} \mathrm{H}-$ proline $(D, E)$ autoradiographs from another six hemispheres in three different animals. $A$ and $B$, Left $(A)$ and right $(B)$ visual cortex of cat N2. $C$ and $F$, Left $(C)$ and right $(F)$ hemisphere of cat N3. $D$ and $E$, Left $(D)$ and right $(E)$ visual cortex of cat N5. 


\section{A}

B
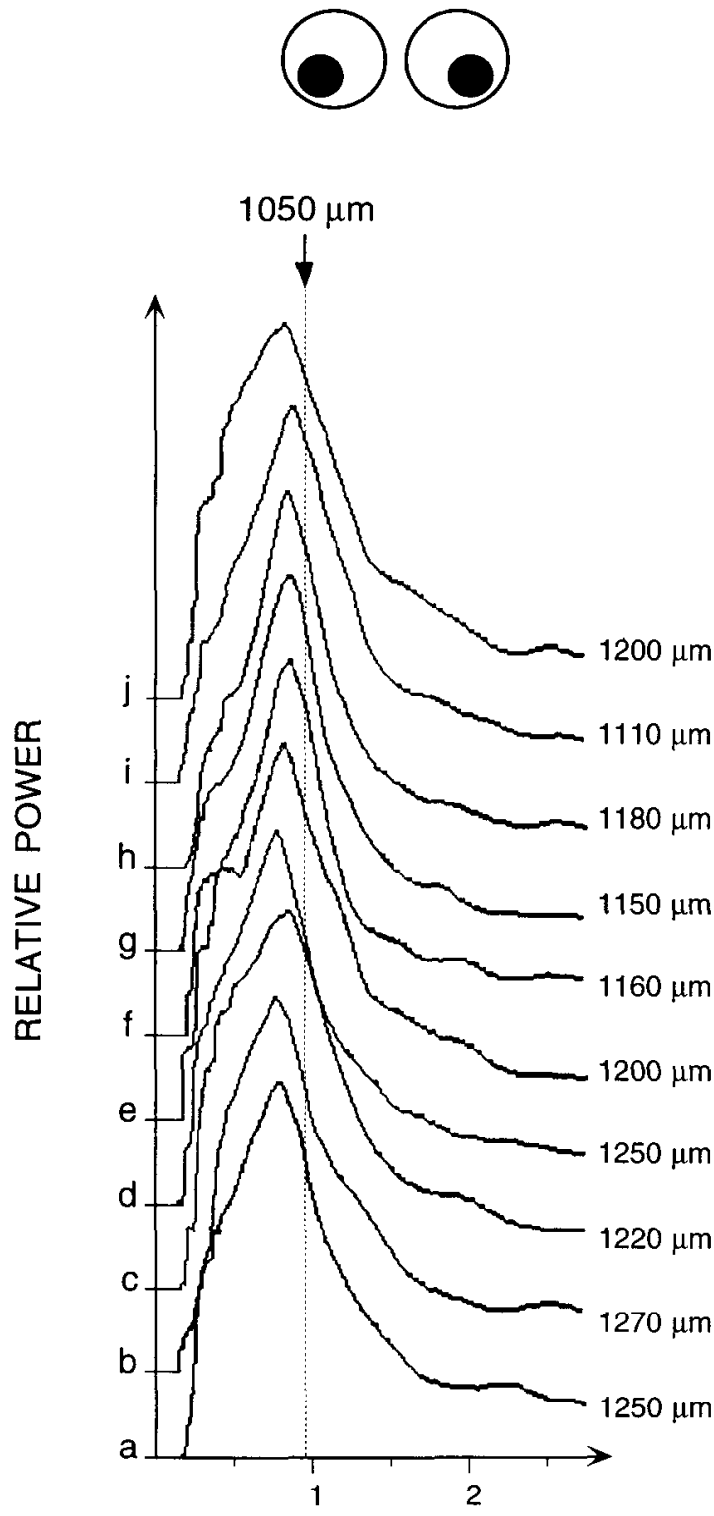

SPATIAL FREQUENCY [cyc/mm]
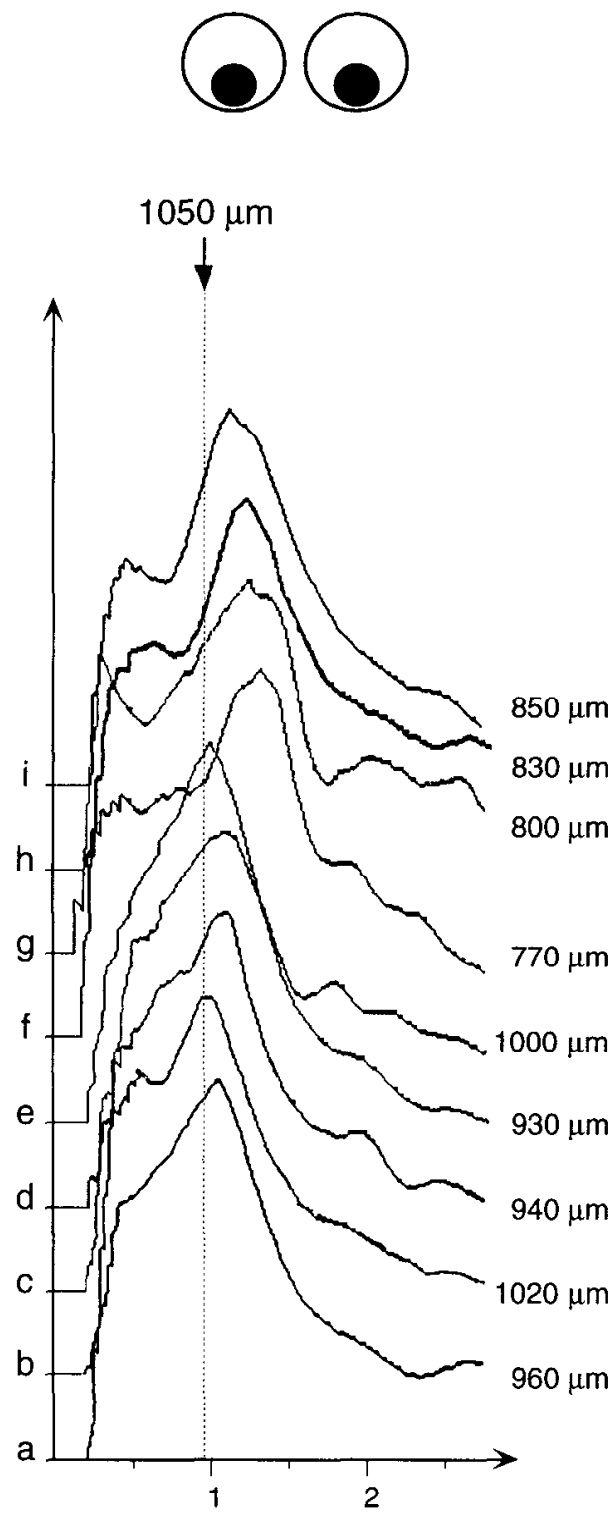

SPATIAL FREQUENCY [cyc/mm]

Figure 5. Spatial frequency analyses of the patterns of ocular dominance columns in the visual cortex of strabismic $(A)$ and normal cats $(B)$ (see also Table 1): one-dimensional Fourier analyses of the ${ }^{3} \mathrm{H}$-proline and ${ }^{14} \mathrm{C}-2-\mathrm{DG}$ autoradiographs. The $x$-axes represent the spatial frequency in cycles/millimeter $(\mathrm{cyc} / \mathrm{mm})$; the respective $y$-axes, the relative power of spectral components (the spectra are stacked to aid comparison). All graphs represent averages along multiple vectors perpendicular to the columnar boundaries. $A$, In the strabismic animals, all spectra $(a-j)$ peak left of the dotted line that represents a column-to-column spacing of $1050 \mu \mathrm{m}$, thereby exhibiting larger spacings, in particular, the spectra peak at $1250 \mu \mathrm{m}$ (right cortex) and $1270 \mu \mathrm{m}$ (left cortex) in cat $\mathrm{S} 1(a, b)$, at 1220 and $1250 \mu \mathrm{m}$ in cat $\mathrm{S} 2(c, d)$, at $1200 \mu \mathrm{m}$ in cat $\mathrm{S} 3(e)$, at $1160 \mu \mathrm{m}$ in cat $\mathrm{S} 4(f)$, at 1150 and $1180 \mu \mathrm{m}$ in cat $\mathrm{S} 5(g, h)$, and at 1110 and $1200 \mu \mathrm{m}$ in cat $\mathrm{S} 6(i, j)$. B, The spectra of the normal animals peak right of the $1050 \mu \mathrm{m}$ line (dotted line), thereby exhibiting smaller spacings, in particular, the spectra peak at $960 \mu \mathrm{m}$ in cat N1 $(a)$, at 1020 and $940 \mu \mathrm{m}$ in cat $\mathrm{N} 2(b, c)$, at 930 and $1000 \mu \mathrm{m}$ in cat $\mathrm{N} 3(d, e)$, at 770 and $800 \mu \mathrm{m}$ in cat $\mathrm{N} 4(f, g)$, and at 830 and $850 \mu \mathrm{m}$ in cat N5 $(h, i)$.

compared to area 17 (see also Cynader et al., 1987; Diao et al., 1990). In contrast, in strabismics, the differences in columnar spacing between areas 17 and 18 is much lower: ocular dominance domains in area 18 are only $1.2-1.4$ times wider than those in area 17 (Table 1, Fig. 9D).

\section{Discussion}

The main result of the present study is that ocular dominance domains in area 17 of strabismic cats are not only more sharply delineated than in normal animals (Shatz et al., 1977), but that 


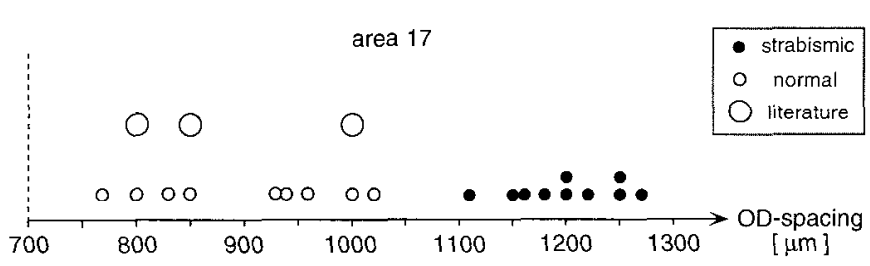

Figure 6. Comparison of the periodicities of the patterns of ocular dominance columns in area 17 of strabismic $(\bullet)$ and normally raised control cats (o). To construct this graph, the peak values of the Fourier spectra in Figure $5 A$ and $B$ were taken. The large open circles represent values published in the literature: Diao et al. (1990), $800 \mu \mathrm{m}$; LeVay et al. (1978), $850 \mu \mathrm{m}$; and Shatz et al. (1977), $1 \mathrm{~mm}$. The $x$-axis represents the spacing of adjacent ocular dominance columns $(O D)$ in micrometers.

the spacing of adjacent domains is different as well: spatial frequency analyses indicate mean periodicities in the order of 1100 $1300 \mu \mathrm{m}$. These values are consistently larger than in normal animals in which distances of $800-1000 \mu \mathrm{m}$ are observed (Shatz et al., 1977; LeVay et al., 1978; Löwel and Singer, 1987; Diao et al., 1990). Since the length of area 17 is the same for animals of both experimental groups, it follows that strabismic cats must have fewer ocular dominance domains compared to normal animals. In cortical area 18, mean spatial frequencies are larger than in area 17 for both normal and strabismic cats and range from $1500-1650 \mu \mathrm{m}$. Therefore, in area 18, the spacing of adjacent ocular dominance domains does not seem to be influenced by strabismus.

\section{Methodological considerations}

Inspection of the ocular dominance columns in area 17 of strabismic cats already shows that the spacing of adjacent domains is larger than in normal animals. Since quantitative analysis of columnar spacings in noisy and irregular patterns such as ocular dominance domains is in general very complicated, emphasis was put on presenting originals (Figs. 1-4). To complement these qualitative observations with quantitative measurements, the spectral content of the patterns of ocular dominance was assessed by one-dimensional Fourier analyses (which has been successfully applied in previous investigations, i.e., Löwel and Singer, 1987; Swindale, 1988). One-dimensional Fourier analysis can be applied to determine columnar spacing because the patterns of ocular dominance columns are not completely patchy but contain numerous elongated slabs or bands (see, e.g., Figs. $1 A, B ; 2 A, B$; Töwel and Singer, 1987; Anderson et al., 1988). Since there is a small but consistent tendency for the ocular dominance domains to be elongated roughly orthogonal to the 17/18 border (Löwel and Singer, 1987; Anderson et al., 1988), most of the measurements were performed parallel to that border, that is, in an anterior-posterior direction.

Why did the observation of a different columnar spacing escape the analyses of a number of working groups who already visualized ocular dominance columns in strabismic cats? One possible clue lies in the usage of flat-mount sections in the present study. Differences in spacing may become apparent only if the complete pattern of ocular dominance domains in the entire area 17 (and 18) is analyzed. Differences may not be easily detected if horizontal sections are studied because usually only some of the columns arc considercd and variability of single column-to-column spacings may be rather high.

Before discussing in detail the difference in spacing, possible artifacts that could influence columnar spacing have to be considered. As already described in the Results, the strabismic and
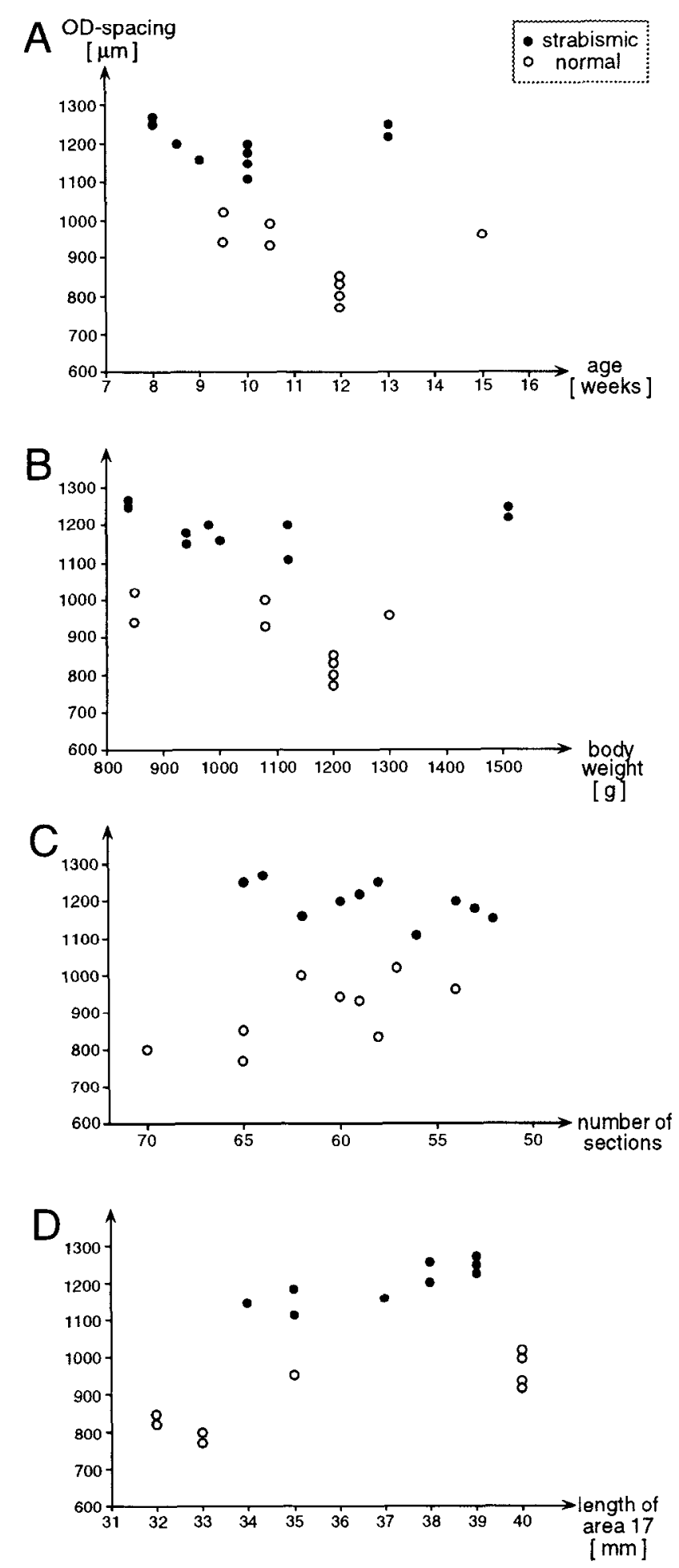

Figure 7. The spacing of adjacent ocular dominance columns $(O D)$ in area 17 of strabismic $(\odot)$ and normal $(O)$ cats as a function of their age $(A)$, body weight $(B)$, number of flat-mount sections $(C)$, and anteriorposterior extent ("length") of area $17(D)$. Note that the spacing of adjacent ocular dominance columns in strabismic animals is always larger than in the normal animals irrespective of age, body weight, number of flat-mount sections, and length of area 17: the solid circles lie always above the open circles. In addition, both experimental groups (strabismic and normally raised cats) consisted of animals of similar age, body weight, number of sections, and length of area 17. 

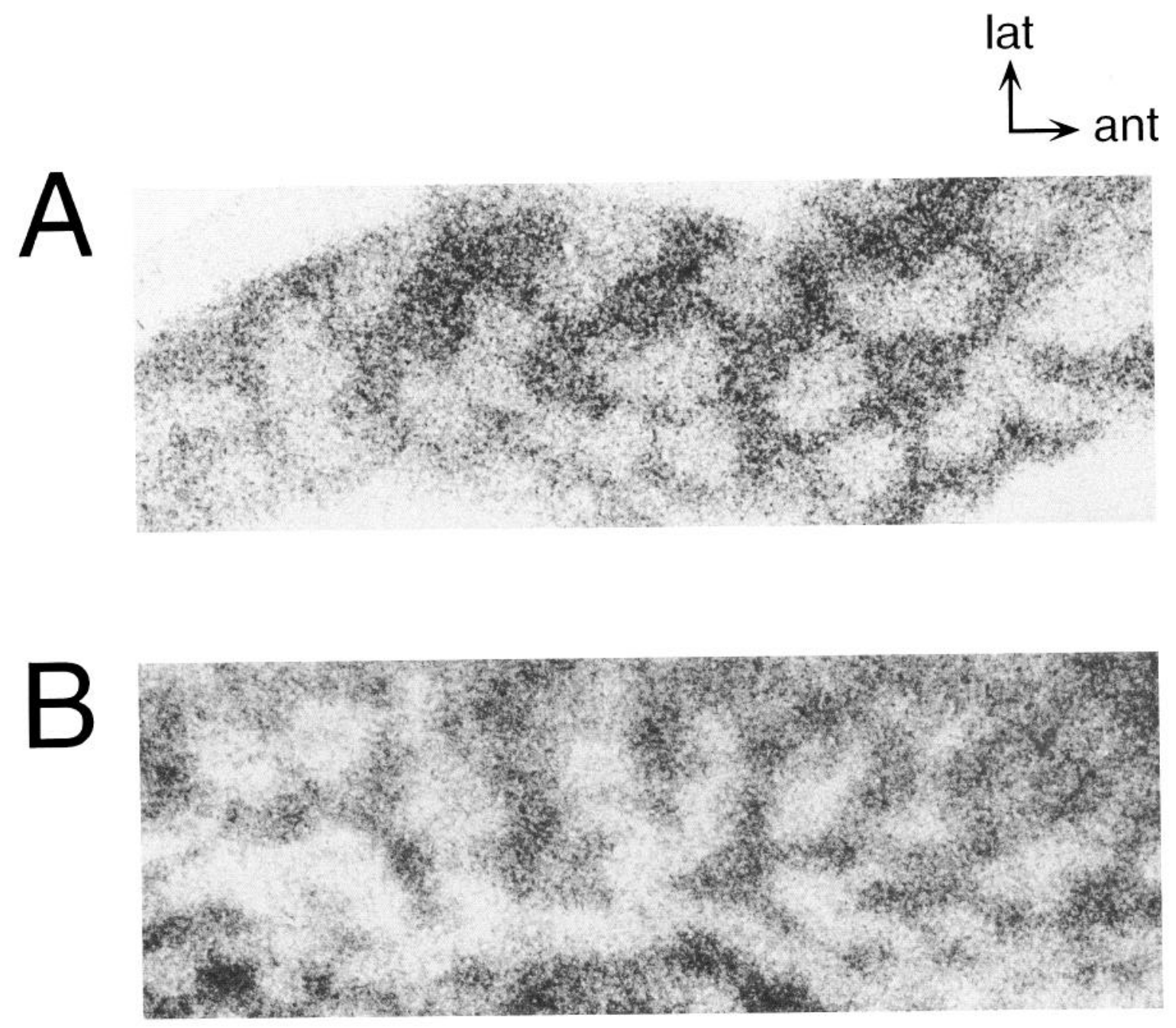

Figure 8. Pattern of ocular dominance columns in area 18 of the strabismic cats $\mathrm{S} 4(A)$ and $\mathrm{S} 2(B):{ }^{3} \mathrm{H}$-proline-labeled columns in layer IV $(A)$ and ${ }^{14} \mathrm{C}$-2-DG-labeled domains in supragranular layer III $(B)$ in hemispheres contralateral to the injected, respectively open eye. In both cats, the domains of the noninjected, respectively closed eye are the lightly labeled regions. Scale bar, $1 \mathrm{~mm}$.

control animals were matched for (1) age, (2) body weight, (3) number of flat-mount sections, and (4) length of area 17. Therefore, none of these factors could have contributed to a difference in columnar spacing. In addition, analysis of the correlation coefficients between the different variables demonstrated that visual experience (strabismic or normal) is the only variable that is significantly correlated with the spacing of adjacent ocular dominance columns (c.c. 0.91). A further possible source of variability is tissue shrinkage. However, it is unlikely that this is responsible for a change in columnar spacing since all sections were unfixed and processed in the same way. Finally, all possible artifacts would be expected to affect area 18 similarly, but they do not appear to do so in the cases examined.

Taken together, the difference in columnar spacing between strabismic and normal cats cannot be artifactual but must be due to the different visual experience these animals had.

\section{Nature versus nurture: activity dependence of columnar spacing}

The results of the present study show that in area 17, but not in area 18 , of strabismic cats, decreased correlation of activity between the eyes leads to larger ocular dominance domains as in normally raised animals. Therefore, the periodicity of the pattern must be influenced by visual experience, and in particular by the temporal patterning of neural activity. That column formation per se is driven by activity-dependent competition between the afferents serving the two eyes has long been known (Hubel et al., 1977; for review, see Stryker, 1986, 1991; Constantine-Paton et al., 1990; Goodman and Shatz, 1993). In addition, monocular deprivation experiments indicated that one eye's domain could increase at the expense of the other eye's domain (Wiesel and Hubel, 1965; Hubel et al., 1977; Shatz and Stryker, 1978; LeVay et al., 1980). These observations still left open the possibility that the spatial layout of the ocular dominance columns is biochemically built in or genetically fixed. The results of the present study are therefore a direct demonstration that the spatial organization of the columns, in particular the spacing of adjacent domains, also develops in an activity-dependent way and that it cannot be determined alone by factors intrinsic to the cortex and independent of the properties of geniculocortical afferents, as was recently suggested by Jones et al. (1991). In addition, the present observations emphasize the im- 
portance of the temporal patterning of neural activity as a crucial factor, not only for the segregation of afferents into distinct columns (Stryker and Strickland, 1984) but also for the final expression of the columnar grid.

\section{Models of column formation}

Most of the numerous models on map formation have dealt with the question of why ocular dominance columns do develop at all (for review, see Constantine-Paton, 1983; Stryker, 1986, 1991 ; von der Malsburg and Singer, 1988; Clothiaux et al., 1991; Goodman and Shatz, 1993). Since ocular dominance bands can arise in species that normally have none, that is, the famous eye-specific termination bands in tecta of three-eyed frogs (Constantine-Paton and Law, 1978; for reviews, see ConstantinePaton, 1983; Udin and Fawcett, 1988), it was argued that column formation may arise as a by-product of more general mechanisms concerned with map formation (Constantine-Paton, 1983). Stripe formation is now generally interpreted as a compromise between two opposing constraints: a retinotopic matching process (during which afferents from the two eyes attempt to connect to postsynaptic neurons as close as possible to their ideal topographic locus in the target structure that limits the size of the same-eye domains) and a sorting mechanism for presynaptic proximity (which "forces" afferents from the same eye to remain together in the target zone to build up a domain of like afferents) (LeVay et al., 1975; Constantine-Paton, 1983).

If we now consider the effectiveness of these two opposing constraints in strabismic animals, it appears almost as a logical consequence that ocular dominance domains should be wider in these animals. Since the optical axes of the two eyes in strabismics are not aligned and the images on the two retinas cannot be brought into register, the responses mediated by anatomically corresponding retinal loci (in the two eyes) are no longer correlated. According to Hebb's postulate for associative learning (Hebb, 1949) and its modern extension by Stent (1973) and Changeux and Danchin (1976), synaptic contacts between synchronously active pre- and postsynaptic neurons are selectively strengthened whereas synaptic contacts between asynchronously active pre- and postsynaptic neurons will be weakened. As a consequence, in strabismics, left and right eye afferents will no longer attempt to innervate topographically identical positions in the visual cortex (lacking binocular "clamp"). On the other hand, since neighboring cells within the same retina do have correlated activities (Adrian and Matthews, 1928; Rodieck and Smith, 1966; Arnett, 1978; Maffei and Galli-Resta, 1990; Meister et al., 1991; for review, see Mastronarde, 1989), synapses driven by each eye will try to maximize their association with synchronously active cells (those driven from the same eye displaying similar patterns of neural activity) and minimize their association with cells asynchronously activated by the other eye (carrying different patterns of activity). Therefore, the reduced between-eye correlations in strabismics should finally lead to a sharper segregation and to larger stripes, predictions that are consistent with the observations of the present study.

Interestingly, again based on considerations that ocular dominance columns could arise as a "by-product of the mechanisms concerned with map formation," a theoretical model was recently presented which explicitly predicted that "reduced between eye correlations should lead to wider stripes" (Goodhill, 1993). In his model, Goodhill investigated the dependence of the pattern of stripes on the degree of correlation between the eyes. An important aspect of his model is that ocular dominance

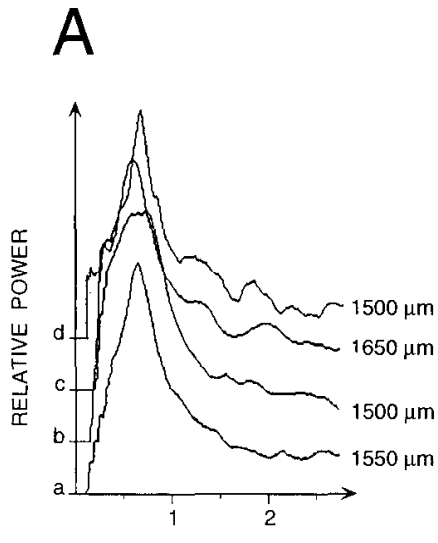

SPATIAL FREQUENCY [cyc/mm]
B

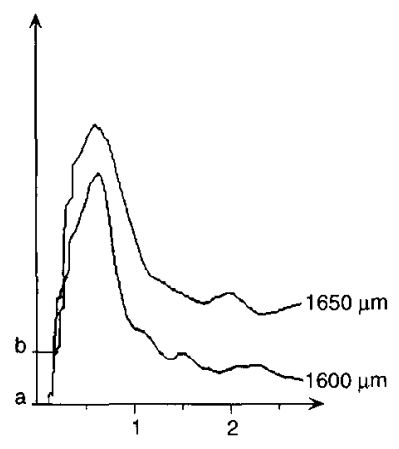

SPATIAL FREQUENCY [cyc/mm]
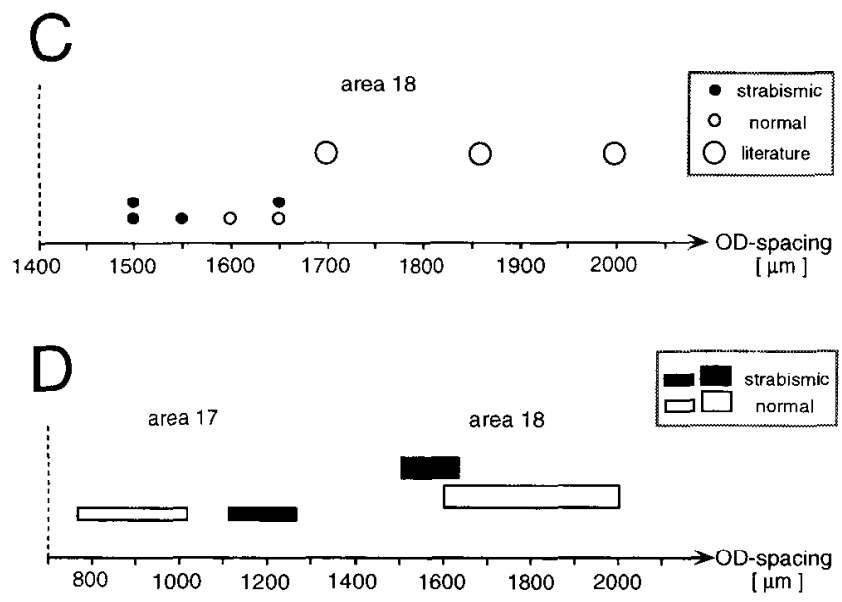

Figure 9. Quantitative analysis of the spacing of ocular dominance columns in strabismic and normal cats. $A$ and $B$, Spatial frequency analyses of the patterns of ocular dominance columns in area 18 of four of the strabismic cats $(A)$ and two of the normal control animals $(B)$ : one-dimensional Fourier analyses of the ${ }^{3} \mathrm{H}$-proline and ${ }^{14} \mathrm{C}-2-\mathrm{DG}$ autoradiographs. The $x$-axes represent the spatial frequency in cycles $/ \mathrm{mil}$ limeter $(\mathrm{cyc} / \mathrm{mm})$; the respective $y$-axes, the relative power of spectral components (the spectra are stacked to aid comparison). All graphs represent averages along multiple vectors perpendicular to the columnar boundaries. The spectra of the strabismic cats $(A)$ peak at $1550 \mu \mathrm{m}$ in cat $\mathrm{S} 1(a)$, at $1500 \mu \mathrm{m}$ in cat $\mathrm{S} 2(b)$, at $1650 \mu \mathrm{m}$ in cat $\mathrm{S} 4(c)$, and at $1500 \mu \mathrm{m}$ in cat $\mathrm{S} 5(d)$. The spectra of the normal cats $(B)$ peak at 1600 $\mu \mathrm{m}$ in cat $\mathrm{N} 2(a)$ and at $1650 \mu \mathrm{m}$ in cat $\mathrm{N} 5(b) . C$, Comparison of the periodicities of the patterns of ocular dominance columns in area 18 of strabismic $(\bullet)$ and normally raised control cats $(O)$. The peak values of the Fourier spectra in $A$ and $B$ were taken to construct this graph. The large open circles represent values published in the literature: Shatz et al. (1977), $1700 \mu \mathrm{m}$ (mean of measurements on the published photoprints); Cynader et al. (1987), $1.86 \mathrm{~mm}$; and Diao et al. (1990), 2000 $\mu \mathrm{m}$. The $x$-axis represents the spacing of adjacent ocular dominance columns $(O D)$ in micrometers. $D$, Range of the periodicities of the ocular dominance system in areas 17 (thin bars) and 18 (thick bars) of normally raised (open bars) and strabismic (solid bars) cats. Results of the present study and values described in the literature are included (see also $C$ and Fig. 6). The $x$-axis represents the spacing of adjacent ocular dominance columns in micrometers. Note that in strabismic cats, the spacing of adjacent domains is larger than in normal cats in area 17 but not in area 18 .

segregation can occur even when the two eyes are positively correlated. In all animals with stereoscopic vision, like cat and monkey, at least some amount of positive correlation between the activities of corresponding regions in the two retinas will be present after eye opening during postnatal development. In contrast, many other models about the development of ocular dom- 
inance columns explored zero or negative between-eye correlations, which is the natural situation before eye opening and during embryonic development (in animals with stereoscopic vision) or in lateral-eyed animals (i.e., von der Malsburg and Willshaw, 1976; Legéndy, 1978; Swindale, 1980; but see Durbin and Mitchison, 1990; Obermayer et al., 1990). According to Goodhill, neighboring cortical cells have competing tendencies to connect with neighboring cells in the same retina (due to within-eye correlations) and corresponding cells in the other retina (due to between-eye correlations). The stronger the correlation between the two eyes, the more often the latter tendency will win, leading to narrower stripes. In contrast, in strabismic animals, the reduced between-eye correlations should lead to wider stripes (Goodhill, 1983), a prediction that is in accordance with the present observations.

In most other models (i.e., von der Malsburg and Willshaw, 1976; Swindale, 1980), stripe width is set primarily by the extent of the cortical interaction function: longer-range excitation between cortical units leads to wider stripes. However, usually, the degree to which positive between-eye correlations could affect stripe width has not been investigated explicitly. In the recently published and very elaborate Miller et al. model (i.e., Miller, 1990), a model that particularly emphasizes the biological plausibility of its assumptions, the set of parameters contributing to the scale of the stripes is expanded by an "arbor function," describing the spread of afferent arbors and of cortical dendrites (Miller et al., 1989). Therefore, again, cortical interactions determine the width of ocular dominance domains up to a possible limit set by arbor diameters. Opposite-eye anticorrelations, as in strabismus, lead to increased monocularity in the cortex "without changing the basic periodicity" (Miller and Stryker, 1990). To account for the increased columnar spacing seen in strabismic cats within the framework of these models, one would have to assume either longer-range excitation or a reduction in long-range inhibition in these animals. Experimentally, these possibilities have not been tested yet. Finally, in even other theoretical concepts, such as "elastic net" models (i.e., Durbin and Mitchison, 1990) or "Kohonen"-type models (i.e., Kohonen, 1982, 1984; Obermayer et al., 1990), the form of input correlations again could be important in influencing stripe width. However, again, the effect of strabismus on the size of ocular dominance columns has not yet been tested explicitly in these models. Therefore, and since a detailed discussion of these different models would go beyond the scope of the present report, the interested reader is referred to Goodhill (1991, 1993) and Miller (1990). Taken together, more than one theoretical concept about map formation and the development of ocular dominance columns may in principle account for the present observations. Future experiments are therefore needed to test the various predictions made by different models in order to select those concepts that are more viable than others.

\section{Cooperative development of geniculocortical afferents and long-range tangential connections?}

As discussed earlier, during map formation the sorting mechanism for presynaptic proximity should favor larger "iso"-eye domains in strabismic compared to normal animals. Therefore, the question remains why stripe width increases "only" to values of $1100-1300 \mu \mathrm{m}$ and not more. In principle, the mapping mechanism as such should not induce any constraints for the size of "iso"-eye domains. However, since an upper limil seems to exist it may help to reveal underlying developmental mech- anisms. Interestingly, the spacing of ocular dominance domains in strabismic cats roughly corresponds to the spacing of isoorientation columns in normal cats, which are in the range of 1000-1300 $\mu \mathrm{m}$ (Löwel et al., 1987; for a review, see LeVay and Nelson, 1991). In addition, it has been shown recently that longrange tangential connections preferentially connect neurons driven by the same eye in strabismic cats (Löwel and Singer, 1992; see also Tychsen and Burkhalter, 1992). To make that possible, tangential connections and ocular dominance columns must be matched in spatial scale. This in turn indicates that the two systems probably influence each other during development. In this context, it is worth considering the time course of development of the two systems. It is not yet known whether the maturation of the intracortical connections precedes the segregation of geniculocortical afferents into ocular dominance columns or whether both patterns attain adult-like organization in the same postnatal period. If anything, in kitten, patchy intrinsic connections may be present some days earlier than ocular dominance domains: crude patches of tangentially connected neurons are already discernible at postnatal day 10 in kittens (Callaway and Katz, 1990; Luhmann et al., 1990), whereas the segregation of left and right eye afferents starts at about 3 weeks of age (LeVay et al., 1978; Shatz and Stryker, 1978). It is therefore possible that the patchy intrinsic connections and the cortical activity pattern they generate serve as a "template" for the segregating geniculocortical afferents so that the latter become matched in periodicity to the patchy intrinsic connections (which in turn are matched to the orientation column system; see Gilbert and Wiesel, 1989; see also von der Malsburg and Singer, 1988 , for a very interesting discussion of developmental interactions of orientation and ocular dominance domains). Alternatively, and probably more likely, is a slightly different scenario: tangential connections and geniculocortical afferents could develop in a cooperative manner. Any changes in the activity of the geniculocortical afferents will influence cortical activity patterns, thereby influencing the pruning of tangential connections. Likewise, changes in tangential connectivity will influence activity correlations in the cortex and thereby affect the stabilization or elimination of afferent synaptic contacts. Finally, in the adult animal, the two systems of connections could evolve into a state of equilibrium, thereby displaying similar spatial periodicities (see also Sirosh and Miikkulainen, 1994).

\section{Spacing of ocular dominance columns in cortical area 18}

As in normally raised cats (Shatz et al., 1977; Cynader et al., 1987; Diao et al., 1990), in area 18 of strabismic animals ocular dominance domains are larger than in area 17. Surprisingly, however, they do not get spaced further than in normal cats. The following two explanations may account for this observation. Either the maximal column-to-column spacing is already reached in the normal cats (so that decreased correlation between the eyes cannot increase the spacing further) or there may be fundamental differences in the development of geniculocortical inncrvation between these two cortical areas (i.e., Fried lander and Martin, 1989).

From a theoretical point of view, "intracortical connections," thalamocortical "arbors, and perhaps correlations" (Miller et al., 1989) may show a difference between the two regions. It is known that area 18 is innervated predominantly by $\mathrm{Y}$-cell axons, whereas area 17 gets input from both $\mathrm{X}$ - and $\mathrm{Y}$-cells. Since $Y$-cell axon arbors are larger $(2 \mathrm{~mm})$ than those of $X$-cell axons (1.5 mm) (LeVay and Stryker, 1979; Humphrey et al., 1985), 
ocular dominance patches in cortical area 18 may develop larger sizes (Miller et al., 1989). In addition, it is possible that stripe width is already at the upper bound allowed by the diameter of afferent arbors so that reduced between-eye correlations do not influence the spatial layout of ocular dominance domains in area 18. Alternatively, the larger ocular dominance columns in area 17 of strabismic cats could also be explained if Y-cell input would dominate this area in these animals. However, no experimental evidence exists in favor of this possibility.

Whereas it is generally believed that the segregation of geniculocortical afferents into ocular dominance columns in area 17 involves retraction of initially expanded and overlapping projections from the left and right eye (Hubel and Wiesel, 1970, 1977; LeVay et al., 1978, 1980; LeVay and Stryker, 1979; Shatz and Luskin, 1986; Antonini and Stryker, 1993), the situation is less clear in cortical area 18. Surprisingly, there are no data in the literature describing the development of ocular dominance columns in area 18 , for example, with intraocular injections of tracers such as horseradish peroxidase (HRP) or ${ }^{3} \mathrm{H}$-proline. The only data available are intracellular fillings of $\mathrm{Y}$-axon arborizations in area 18 of kittens and cats (Friedlander and Martin, 1989) and very recently also chronic optical imaging of the functional architecture of kitten area 18 (Bonhoeffer et al., 1993). Friedlander and Martin's investigations demonstrate that in the 4-5-week-old kitten, axonal arbors are smaller than those in the adult, indicating that thalamocortical inncrvation develops by a moderate expansion, rather than retraction, of the arborizations (Friedlander and Martin, 1989). The optical recording experiments reveal, as early as in 3-week-old kittens, topographically separate functional maps for the right and left eye (Bonhoeffer et al., 1993). In addition, Milleret et al. (1988) reported that the percentage of binocularly activated cortical neurons increases dramatically between 2 and 4 weeks of age. The physiological development of binocularity in area 18 does therefore not seem to mirror that in area 17 , which may be taken as an indication of differences in the development of geniculocortical innervation between the two cortical areas (Friedlander and Martin, 1989). It is therefore conceivable that reduced betweeneye correlations do not influence the development of the eyespecific domains in area 18 in a similar way as in cortical area 17.

\section{Conclusions}

(1) In area 17 (but not in area 18) of strabismic cats, decreased correlation between the eyes alters the periodicity of ocular dominance columns: the column-to-column spacing is on average $20-30 \%$ larger than in normally raised animals.

(2) These results indicate that not only the segregation of afferents into distinct columns but also the final expression of the columnar grid is influenced by visual experience and in particular by the temporal patterning of neural activity.

(3) These findings are further and direct evidence for the hypothesis that the development of ocular dominance columns is governed by activity-dependent self-organizing principles.

(4) Since strabismus also changes the specificity of horizontal connections in area 17 and since the "sculpting" of the intracortical fibers and the segregation of geniculocortical afferents into ocular dominance columns occurs at the same postnatal period, more complex (and possibly cooperative) interactions between the two developing systems than previously thought are likely to happen.

\section{References}

Adrian ED, Matthews R (1928) The action of light on the eye. Part III. The interaction of retinal neurones. J Physiol (Lond) 65:273-298. Anderson PA, Olavarria J, Van Sluyters RC (1988) The overall pattern of ocular dominance bands in cat visual cortex. J Neurosci 8:21832200.

Antonini A, Stryker MP (1993) Development of individual geniculocortical arbors in cat striate cortex and effects of binocular impulse blockade. J Neurosci 13:3549-3573.

Arnett DW (1978) Statistical dependence between neighbouring retinal ganglion cells in goldfish. Exp Brain Res 32:49-53.

Bonhoeffer T, Kim D-S, Singer W (1993) Optical imaging of the reverse suturing effect in kitten visual cortex during the critical period. Soc Neurosci Abstr 19:737.4.

Callaway EM, Katz LC (1990) Emergence and refinement of clustered horizontal connections in cat striate cortex. J Neurosci 10:1134-1153.

Changeux J-P, Danchin A (1976) Selective stabilisation of developing synapses as a mechanism for the specification of neuronal networks. Nature 264:705-712.

Clothiaux EE, Bear MF, Cooper LN (1991) Synaptic plasticity in visual cortex: comparison of theory with experiment. J Neurophysiol 66: 1785-1804.

Constantine-Paton M (1983) Position and proximity in the development of maps and stripes. Trends Neurosci 6:32-36.

Constantine-Paton M, Law MI (1978) Eye-specific termination bands in tecta of three-eyed frogs. Science 202:639-641.

Constantine-Paton M, Cline HT, Debski E (1990) Patterned activity, synaptic convergence, and the NMDA receptor in developing visual pathways. Annu Rev Neurosci 13:129-154.

Cynader MS, Swindale NV, Matsubara JA (1987) Functional topography in cat area 18. J Neurosci 7:140I-1413.

Diao Y-c, Jia W-g, Swindale NV, Cynader MS (1990) Functional organization of the cortical $17 / 18$ border region in the cat. Exp Brain Res 79:271-282.

Durbin R, Mitchison G (1990) A dimension reduction framework for understanding cortical maps. Nature 343:644-647.

Freeman B, Löwel S, Singer W (1987) Deoxyglucose mapping in the cat visual cortex following carotid artery injection and cortical flatmounting. J Neurosci Methods 20:115-129.

Friedlander MJ, Martin KAC (1989) Development of Y-axon innervation of cortical area 18 in the cat. J Physiol (Lond) 416:183-213.

Gilbert CD, Wiesel TN (1989) Columnar specificity of intrinsic horizontal and corticocortical connections in cat visual cortex. J Neurosci 9:2432-2442.

Goodhill GJ (1991) Correlations, competition and optimality: modelling the development of topography and ocular dominance. $\mathrm{PhD}$ thesis, Sussex University.

Goodhill GJ (1993) Topography and ocular dominance: a model exploring positive correlations. Biol Cybern 69:109-118.

Goodman CS, Shatz CJ (1993) Developmental mechanisms that generate precise patterns of neuronal activity. Cell 72:77-98.

Grafstein B (1971) Transneuronal transfer of radioactivity in the central nervous system. Science 172:177-179.

Hebb DO (1949) The organization of behavior. A neuropsychologica theory. New York: Wiley.

Hubel DH, Wiesel TN (1965) Binocular interaction in striate cortex of kittens reared with artificial squint. J Neurophysiol 28:1041-1059

Hubel DH, Wiesel TN (1970) The period of susceptibility to the physiological effects of unilateral eye closure in kittens. J Physio (Lond) 206:419-436.

Hubel DH, Wiesel TN (1977) Functional architecture of macaque monkey visual cortex. Proc R Soc Lond [Biol] 198:1-59.

Hubel DH, Wiesel TN, LeVay S (1977) Plasticity of ocular dominance columns in monkey striate cortex. Philos Trans R Soc Lond [Biol 278:377-409.

Humphrey AI, Sur M, Uhlrich DJ, Sherman SM (1985) Projectior patterns of individual $\mathrm{X}$ - and $\mathrm{Y}$-cell axons from the lateral geniculats nucleus to cortical area 17 in the cat. J Comp Neurol 233:159-189.

Jones DG, Van Sluyters RC, Murphy KM (1991) A computationa model for the overall pattern of ocular dominance. J Neurosci 11 3794-3808.

Kalil RE (1982) Development of ocular dominance columns in cat: reared with binocular deprivation or strabismus. Soc Neurosci Abst] 8:5.9. 
Kohonen T (1982) Self-organized formation of topologically correct feature maps. Biol Cybern 43:59-69.

Kohonen T (1984) Self-organization and associative memory. Heidelberg: Springer.

Legéndy CR (1978) Cortical columns and the tendency of neighboring neurons to act similarly. Brain Res 158:89-105.

LeVay S, Gilbert CD (1976) Laminar patterns of geniculocortical projection in the cat. Brain Res 113:1-19.

LeVay S, Nelson SB (1991) Columnar organization of the visual cortex. In: The neural basis of visual function (Leventhal AG, ed), pp 266-315. Houndmills: Macmillan.

LeVay S, Stryker MP (1979) The development of ocular dominance columns in the cat. In: Society for neuroscience symposium: aspects of developmental neurobiology (Ferrendelli JA, ed), pp 83-98. Bethesda, MD: Society for Neuroscience.

LeVay S, Hubel DH, Wiesel TN (1975) The pattern of ocular dominance columns in macaque visual cortex revealed by a reduced silver stain. J Comp Neurol 159:559-576

LeVay S, Stryker MP, Shatz CJ (1978) Ocular dominance columns and their development in layer IV of the cat's visual cortex: a quantitative study. J Comp Neurol 179:223-244.

LeVay S, Wiesel TN, Hubel DH (1980) The development of ocular dominance columns in normal and visually deprived monkeys. $\mathrm{J}$ Comp Neurol 191:1-51.

Löwel S, Singer W (1987) The pattern of ocular dominance columns in flat-mounts of the cat visual cortex. Exp Brain Res 68:661-666.

Löwel S, Singer W (1992) Selection of intrinsic horizontal connections in the visual cortex by correlated neuronal activity. Science 255:209212.

Löwel S, Singer W (1993a) Monocularly induced 2-deoxyglucose patterns in the visual cortex and lateral geniculate nucleus of the cat: $I$. Anaesthetized and paralyzed animals. Eur J Neurosci 5:846-856.

Löwel S, Singer W (1993b) Monocularly induced 2-deoxyglucose patterns in the visual cortex and lateral geniculate nucleus of the cat: II. Awake animals and strabismic animals. Eur J Neurosci 5:857-869.

Löwel S, Singer W (1993c) Experience-dependent patterning of cortical connections in the visual system of cats. In: Proceedings of the 21 st Göttingen neurobiology conference, Genes, brain and behaviour (Elsner N, Heisenberg M, eds), p 42. Stuttgart: Thieme.

Löwel S, Singer W (1993d) Strabismus changes the spacing of ocular dominance columns in the visual cortex of cats. Soc Neurosci Abstr 19:359.2.

Löwel S, Freeman B, Singer W (1987) Topographic organization of the orientation column system in large flat-mounts of the cat visual cortex: a 2-deoxyglucose study. J Comp Neurol 255:401-415.

Löwel S, Bischof H-J, Leutenecker B, Singer W (1988) Topographic relations between ocular dominance and orientation columns in the cat striate cortex. Exp Brain Res 71:33-46.

Luhmann HJ, Singer W, Martínez-Millán L (1990) Horizontal interactions in cat striate cortex: I. Anatomical substrate and postnatal development. Eur J Neurosci 2:344-357.

Maffei L, Galli-Kesta L (1990) Correlation in the discharges of neighboring rat retinal ganglion cells during prenatal life. Proc Natl Acad Sci USA 87:2861-2864.

Mastronarde DN (1989) Correlated firing of retinal ganglion cells. Trends Neurosci 12:75-80.

Meister M, Wong ROL, Baylor DA, Shatz CJ (1991) Synchronous bursts of action potentials in ganglion cells of the developing mammalian retina. Science 252:939-943.

Meyer RL (1982) Tetrodotoxin blocks the formation of ocular dominance columns in goldfish. Science 218:589-591.

Miller KD (1990) Correlation-based models of neural development. In: Neuroscience and connectionist theory (Gluck MA, Rumelhart DE, eds), pp 267-353. Hillsdale, NJ: Erlbaum.

Miller KD, Stryker MP (1990) The development of ocular dominance columns: mechanisms and models. In: Connectionist modeling and brain function: the developing interface (Hanson SJ, Olson CR, eds), pp 255-305. Cambridge, MA: MIT Press.

Miller KD, Keller JB, Stryker MP (1989) Ocular dominance column development: analysis and simulation. Science 245:605-615.

Milleret C, Gary-Bobo E, Buisseret P (1988) Comparative develop- ment of cell properties in cortical area 18 of normal and dark-reared kittens. Exp Brain Res 71:8-20.

Mower GD, Caplan CJ, Christen WG, Duffy FH (1985) Dark rearing prolongs physiological but not anatomical plasticity of the cat visual cortex. J Comp Neurol 235:448-466.

Obermayer K, Ritter H, Schulten K (1990) A principle for the formation of the spatial structure of cortical feature maps. Proc Natl Acad Sci USA 90:8245-8349.

Rodieck RW, Smith PS (1966) Slow dark discharge rhythms of cat retinal ganglion cells. J Neurophysiol 29:942-953.

Shatz CJ, Luskin MB (1986) The relationship between the geniculocortical afferents and their cortical target cells during development of the cat's primary visual cortex. J Neurosci 6:3655-3668.

Shatz CJ, Stryker MP (1978) Ocular dominance in layer IV of the cat's visual cortex and the effects of monocular deprivation. I Physiol (Lond) 281:267-283.

Shatz CJ, Lindström S, Wiesel TN (1977) The distribution of afferents representing the right and left eyes in the cat's visual cortex. Brain Res 131:103-116.

Sirosh J, Miikkulainen R (1994) Self-organizing feature maps with lateral connections: modeling ocular dominance. In: Proceedings of the connectionist models summer school (Mozer MC, Smolensky P, Touretzky DS, Elman JL, Weigend AS, eds), in press. Hillsdale, NJ; Erlbaum.

Sokoloff L, Reivich M, Kennedy C, Des Rosiers MH, Patlak CS, Pettigrew KD, Sakurada O, Shinohara M (1977) The $\left[{ }^{14} \mathrm{C}\right]$ deoxyglucose method for the measurement of local cerebral glucose utilization: theory, procedure, and normal values in the conscious and anesthetized albino rat. I Neurochem 28:897-916.

Stent GS (1973) A physiological mechanism for Hebb's postulate of learning. Proc Natl Acad Sci USA 70:997-1001.

Stryker MP (1986) The role of neural activity in rearranging connections in the central visual system. In: The biology of change in otolaryngology (Ruben RJ, Van De Water TR, Rubel EW, eds), pp 211 224. Amsterdam: Elsevier.

Stryker MP (1991) Activity-dependent reorganization of afferents in the developing mammalian visual system. In: Development of the visual system (Lam DM-K, Shatz CJ, eds), pp 267-287. Cambridge, MA: MIT Press.

Stryker MP, Harris WA (1986) Binocular impulse blockade prevents the formation of ocular dominance columns in cat visual cortex. J Neurosci 6:2117-2133.

Stryker MP, Strickland SL (1984) Physiological segregation of ocular dominance columns depends on the pattern of afferent electrical activity. Invest Ophthalmol Vis Sci [Suppl] 25:278.

Swindale NV (1980) A model for the formation of ocular dominance stripes. Proc R Soc Lond [Biol] 208:243-264.

Swindale NV (1981) Absence of ocular dominance patches in darkreared cats. Nature 290:332-333.

Swindale NV (1988) Role of visual experience in promoting segregation of eye dominance patches in the visual cortex of the cat. $\mathbf{J}$ Comp Neurol 267:472-488.

Tychsen L, Burkhalter A (1992) Naturally strabismic primate lacks intrinsic horizontal connections for binocular vision in striate cortex. Soc Neurosci Abstr 18:611.9.

Udin SB, Fawcett JW (1988) Formation of topographic maps. Annu Rev Neurosci 11:289-327.

von der Malsburg C, Singer W (1988) Principles of cortical network organization. In: Dahlem workshop reports: neurobiology of neocortex (Rakic P, Singer W, eds), pp 69-99. New York: Wiley.

von der Malsburg C, Willshaw DJ (1976) A mechanism for producing continuous neural mappings: ocularity dominance stripes and ordered retino-tectal projections. Exp Brain Res [Suppl] 1:463-469.

von Noorden GK (1990) Binocular vision and ocular motility. Theory and management of strabismus. St. Louis: Mosby.

Wiesel TN, Hubel DH (1965) Comparison of the effects of unilateral and bilateral eye closure on cortical unit responses in kittens. J Neurophysiol 28:1029-1040.

Wiesel TN, Hubel DH, Lam DMK (1974) Autoradiographic demonstration of ocular-dominance columns in the monkey striate cortex by means of transneuronal transport. Brain Res 79:273-279. 